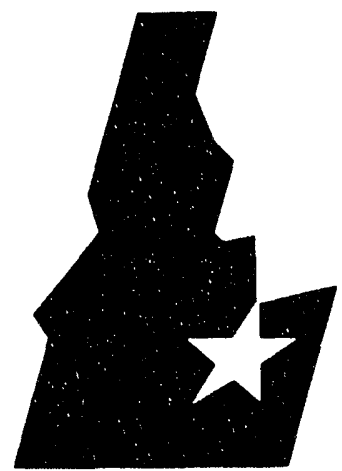

Idaho National

Engineering Laboratory

Managed by the U.S. Department of Energy
EGG-BNCT-10016 -03/04
September 1992

INEL BNCT RESEARCH PROGRAM MARCH/APRIL 1992

J. R. Venhuizen

\section{¿SEERE Idsho}

Work performed under DOE Contract No. DE-AC07-761D01570 


\title{
INEL BNCT Research Program March/April 1992
}

J. R. Venhuizen

Published September 1992

\author{
Idaho National Engineering Laboratory \\ EG\&G Idaho, Inc. \\ Idaho Falls, Idaho $\mathbf{8 3 4 1 5}$
}

Prepared for the

U.S. Department of Energy

Under DOE Field Office, Idaho

Contract DE-AC07-76ID01570

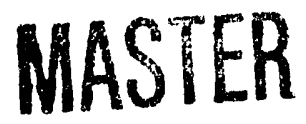

DISTRIBUTION OF THIS DOCUMENT IS UNLIMITED

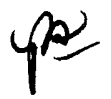




\begin{abstract}
This report presents summaries for two months of current research for the Idaho National Engineering Laboratory (INEL) Boron Neutron Capture Therapy (BNCT) Program. Information is presented on development and murine screening experiments of low-density lipoprotein, carboranyl alanine, and liposome boron containing compounds. Pituitary tumor cell culture studies are described. Drug stability, pharmacology and toxicity evaluation of borocaptate sodium (PSH) and boronophenylalanine (BPA) are described. Treatment protocol development via the large animal (canine) model studies and physiological response evaluation in rats are discussed. Supporting technology development and technical support activities for boron drug biochemistry and purity, analytical and measurement dosimetry, and noninvasive boron quantification activities are included for the current time period. Current publications for the two months are listed.
\end{abstract}

\title{
DISCLAIMER
}

This report was prepared as an account of work sponsored by an agency of the United States Government. Neither the United States Government nor any agency thereof, nor any of their employees, makes any warranty, express or implied, or assumes any legal liability or responsibility for the accuracy, completeness, or usefulness of any information, apparatus, product, or process disclosed, or represents that its use would not infringe privately owned rights. Reference herein to any specific commercial product, process, or service by trade name, trademark, manufacturer, or otherwise does not necessarily constitute or imply its endorsement, recommendation, or favoring by the United States Government or any agency thereof. The views and opinions of authors expressed herein do not necessarily state or reflect those of the United States Government or any agency thereof. 


\section{CONTENTS}

ACRONYMS AND ABBREVIATIONS $\ldots \ldots \ldots \ldots \ldots \ldots \ldots$

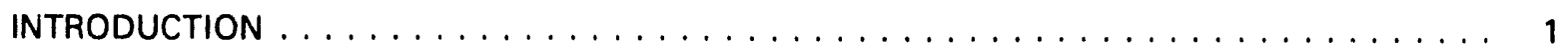

PROGRAM OVERVIEW $\ldots \ldots \ldots \ldots \ldots \ldots \ldots \ldots$

Brain Tumor-BSH Studies $\ldots \ldots \ldots \ldots \ldots \ldots \ldots \ldots \ldots$

Boron Delivery Vehicle Development and Screening . . . . . . . . . . . . . . . . 2

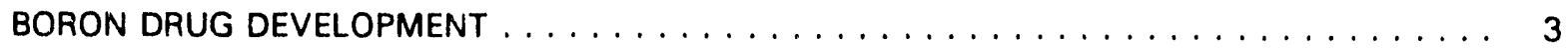

Carboranyl Alanine and LDL Development and Evaluation . . . . . . . . . . . . . . . 3

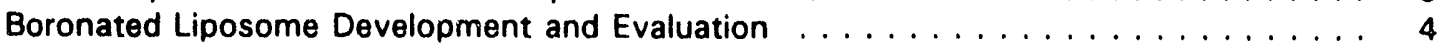

Pituitary Tumor Evaluation $\ldots \ldots \ldots \ldots \ldots \ldots \ldots$

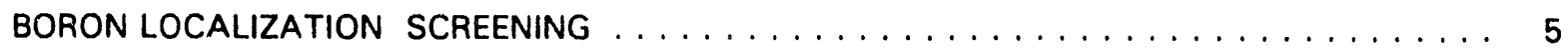

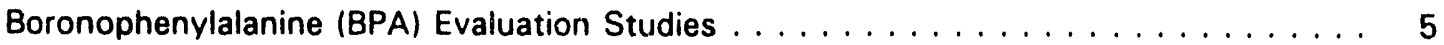

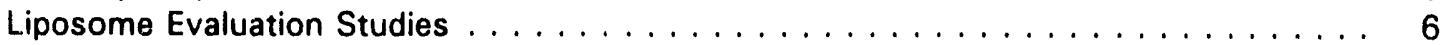

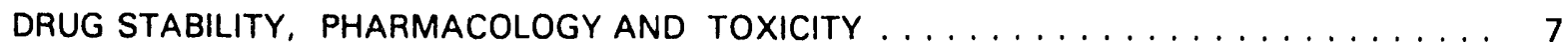

Toxicological Evaluation of $\mathrm{BSH} \ldots \ldots \ldots \ldots \ldots \ldots \ldots$

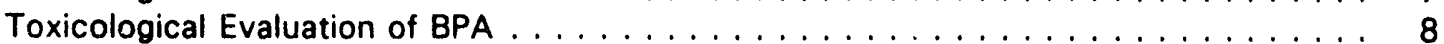

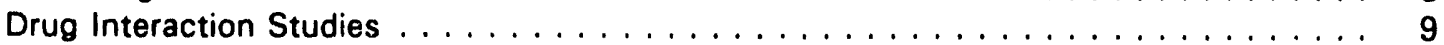

TREATMENT PROTOCOL DEVELOPMENT $\ldots \ldots \ldots \ldots \ldots \ldots \ldots \ldots$

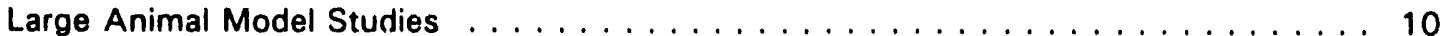

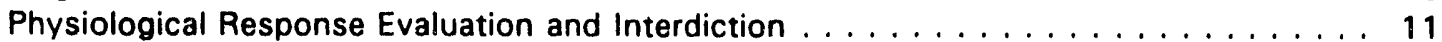

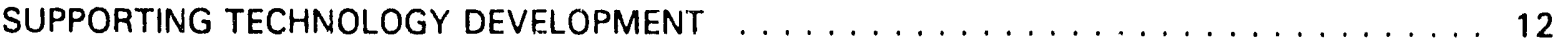

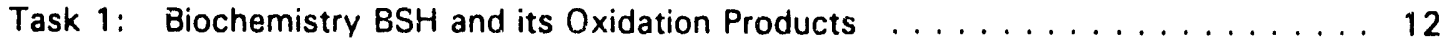

Task 2: Noninvasive Boron Quantification . . . . . . . . . . . . . . . . . . . . . . 12

Task 3: Real-Time Measurement Dosimetry Research . . . . . . . . . . . . . . . . . . . . . 12

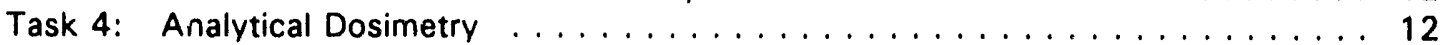

Task 4A: Macrodosimetric Model Development . . . . . . . . . . . . . 12

Task 4B: Microdosimetric Model Development . . . . . . . . . . . . . 13

Task 4C: Microdosimetric Cellular Response Study . . . . . . . . . . . . . 13

Task 4D: Proton-Induced Biological Damage Study . . . . . . . . . . . . . 13

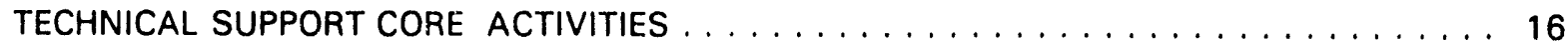

Task 1: ICP-AES Analyses of Boron in Biological Samples . . . . . . . . . . . . . . 16

Task 2: Boron Compound Purity Determinations . . . . . . . . . . . . . . . . . . . . 16

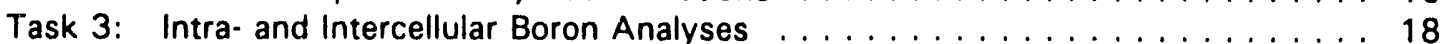

Task 4: Neutron Beam Measurement Dosimetry . . . . . . . . . . . . . . . . . . . 21

Task 5: Canine Dosimetry Calculations . . . . . . . . . . . . . . . . . . . . . . . 21

Task 6: BNCT Database Management System . . . . . . . . . . . . . . . . . . . . . 21

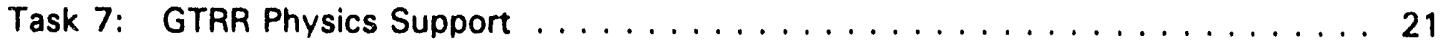

Task 8: Research Reactor/Accelerator Physics Support . . . . . . . . . . . . . . 21

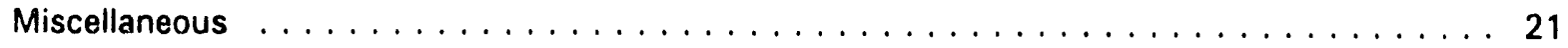

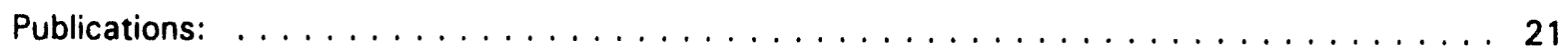




\section{FIGURES}

1. Healthy tissue complications in dogs vs blood-boron and physical dose . . . . . . . . 2

2. Low levels of Phenylalanine and tyrosine enhance BL6 cellular boron uptake . . . . . 6

3. Equilibrium dialysis binding curves in $0.5 \mathrm{~mL}$ protein $\ldots \ldots \ldots$

4. FTIR standard curve for BSH in the presence of $40 \mu \mathrm{g} / \mathrm{mL}$ phenobarbital . . . . . . . . 10

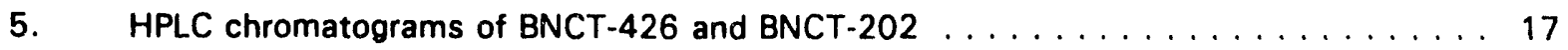

6. Infrared spectra of $\mathrm{BSH}$ samples in $\mathrm{KBr}$ pellets $\ldots \ldots \ldots \ldots$

7. Cross sectional view of the TFS surface analyzer $\ldots \ldots \ldots \ldots$

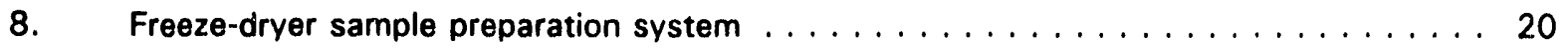

\section{TABLES}

1. LDL reconstitutions (Batch $L W-1-19) \ldots \ldots \ldots \ldots$

2. Oxidation products in various BSH samples as determined by HPLC . . . . . . . 17

3. ICP-AES analysis of BSH compounds $\ldots \ldots \ldots \ldots \ldots$

4. CHN combustion analysis results $(3 / 11 / 92) \ldots \ldots \ldots \ldots \ldots$ 


\section{AC.3ONYMS AND ABBREVIATIONS}

\begin{tabular}{|c|c|c|c|}
\hline ACTH & Adrenocorticotrophic hormone & GH & Growth hormone \\
\hline ANS & American Nuclear Society & GTRR & $\begin{array}{l}\text { Georgia Institute of } \\
\text { Technology Research Reactor }\end{array}$ \\
\hline ASI & Atom Sciences, Inc. & CY & G. \\
\hline$B / C$ & Boron-to-carbon & & \\
\hline BMRR & $\begin{array}{l}\text { Brookhaven Medical Research } \\
\text { Reactor }\end{array}$ & HPLC & $\begin{array}{l}\text { High Performance Liquid } \\
\text { Chromatography }\end{array}$ \\
\hline BNL & $\begin{array}{l}\text { Brookhaven National } \\
\text { Laboratory }\end{array}$ & $\begin{array}{l}\text { HRP } \\
\text { HSA }\end{array}$ & $\begin{array}{l}\text { Horse radish peroxidose } \\
\text { Human serum albumin }\end{array}$ \\
\hline BNCT & $\begin{array}{l}\text { Boron Neutron Capture } \\
\text { Therapy }\end{array}$ & HZEF & Hit size effectiveness function \\
\hline BPA & Boronophenylalanine & ICP-AES & $\begin{array}{l}\text { Inductively Coupled Plasma- } \\
\text { Atomic Emission } \\
\text { Spectroscopy }\end{array}$ \\
\hline BSA & Bovine serum albumin & INEL & Idaho National Engineering \\
\hline BSH & $\begin{array}{l}\text { Borocaptate Sodium } \\
\left(\mathrm{Na}_{2} \mathrm{~B}_{12} \mathrm{H}_{1} \mathrm{SH}\right)\end{array}$ & ISU & Laboratory \\
\hline BSS & $\mathrm{B}_{24} \mathrm{H}_{22} \mathrm{SS}^{4}$ & IV & Intravenous \\
\hline BSSO & $\mathrm{B}_{24} \mathrm{H}_{22} \mathrm{~S}_{2} \mathrm{O}^{4-}$ & KCS & Keratonconjunctivities sicca \\
\hline CE\&A & Charles Evans and Associates & LDL & \\
\hline CGY & Centigray & LET & Linear energy transfer \\
\hline $\mathrm{CHN}$ & Carbon-hydrogen-nitrogen & LM & Light microscopy \\
\hline $\mathrm{CHO}$ & Chinese hainster ovary & LMIG & Liquid metal ion gun \\
\hline CNS & Central nervous system & MRI & Magnetic resonance imaging \\
\hline DEA & Diethanolamine & MSU & Montana State University \\
\hline DOE & Department of Energy & NCAR & National Academy of Sciences \\
\hline ECC & Elaidyl carborane carboxylate & NMR & Nuclear magnetic resonance \\
\hline EKG & Electrocardiogram & NTC & Neutron Technology \\
\hline EM & Electron microscopy & & Corporation \\
\hline FTIR & $\begin{array}{l}\text { Fourier Transform Infrared } \\
\text { Spectroscopy }\end{array}$ & NWI & Northwest Imaging \\
\hline FY & Fiscal year & ORSU & Oregon State University \\
\hline GE & General Electric & OHSU & $\begin{array}{l}\text { Oregon Health Sciences } \\
\text { University }\end{array}$ \\
\hline
\end{tabular}




\begin{tabular}{|c|c|}
\hline PAL & Phenylalanine ammonia lyase \\
\hline PMT & Photo multiplier tube \\
\hline PNL & Pacific Northwest Laboratory \\
\hline PPM & Parts per million \\
\hline RBE & $\begin{array}{l}\text { Relative Biological } \\
\text { Effectiveness }\end{array}$ \\
\hline RíA & Radioimmunoassay \\
\hline RIS & $\begin{array}{l}\text { Resonance ionization } \\
\text { spectroscopy }\end{array}$ \\
\hline RPD & Relative percent difference \\
\hline SIMS & $\begin{array}{l}\text { Secondary Ion Mass } \\
\text { Spectrometry }\end{array}$ \\
\hline SIRIS & $\begin{array}{l}\text { Sputter-Initiated Resonance } \\
\text { lonization Spectroscopy }\end{array}$ \\
\hline TBAS & Tetra bulyl ammonium sulfate \\
\hline TOF & Time-of-flight \\
\hline UCLA & $\begin{array}{l}\text { University of California Los } \\
\text { Angeles }\end{array}$ \\
\hline UCSF & $\begin{array}{l}\text { University of California San } \\
\text { Francisco }\end{array}$ \\
\hline UofR & University of Rochester \\
\hline UofU & University of Utah \\
\hline UTMRF & $\begin{array}{l}\text { University of Tennessee } \\
\text { Medical Research Foundation }\end{array}$ \\
\hline WSU & Washington State Universı. \\
\hline
\end{tabular}




\section{INEL BNCT RESEARCH PROGRAM \\ MARCH/APRIL 1992}

\section{INTRODUCTION}

This bulletin contains an overview of progress for the Idaho National Engineering Laboratory (INEL) Boron Neutron Capture Therapy (BNCT) Research Program for March/April 1992, including information on the research programs, technical support details, and miscellaneous project information.

This month's bulletin is a radical departure from the previous bulletins. This change is the result of combining the Department of Energy (DOE) Monthly Report and the Monthly Bulletin, and rearranging the information reported to represent those portions of the former program that are still funded into a bimonthly bulletin for the revised INEL BNCT Research Program.

Funding for FY-92 and programmatic priorities have been established. The revised Program emphasizes new drug development and screening in progressively more representative and costly models beginning with cell cultures and progressing to large animals. Canine studies, required to establish potential borocaptate sodium (BSH) merit as a brain tumor treatment agent, will be completed. However, the revised Program suspends all activities based on the presumption of BSH efficacy and specificity directed toward human clinical trials. Work on several tasks has been suspended because of Program redirection and FY-92 funding limitations.

\section{PROGRAM OVERVIEW}

\section{Brain Tumor-BSH Studies}

Canine studies have been the focus of INEL $\mathrm{BSH} / \mathrm{brain}$ tumor research for six years. These studies are intended to: (a) demonstrate maximum achievable tumor destruction at normalbrain tolerance, preferably in terms of tumor cell destruction fractions, (b) define relative biological effectiveness (RBE) of the $\left(n, n^{\prime}\right) p$ dose component resulting from residual incident, fast-neutrons, and (c) define vasculature RBE for ${ }^{10} \mathrm{~B}(\mathrm{n}, a)^{7} \mathrm{Li}$ reactions occurring within the lumen volume. It is hypothesized that these results can be analytically combined, with human tumor to blood-boron ratios (supplied by others) and human cranial geometry, to predict human tumor response.

Limiting, normal-tissue canine central nervous system (CNS) tolerance has been established (with a precision of approximately $\pm 15 \%$ ) at two boron concentrations ( 25 and 50 parts per million (ppm) as shown in Figure 1). CNS injury without boron present has not yet been determined because it did not occur at $10 \mathrm{~Gy}$ or $12.5 \mathrm{~Gy}$ and lethal dermal necrosis occurred at $15 \mathrm{~Gy}$ with onset prior to CNS injury latency.

Analysis of the worldwide BNCT data base predicts the following RBE estimates for $\mathrm{BSH}$ :

\section{Current Basis for Normal} Vascular Response Prediction

\begin{tabular}{|c|c|}
\hline Dose Mechanism & $\underline{\mathrm{RBE}}$ \\
\hline Gamma & $\begin{array}{l}\sim 1.0 \text { (rate } \\
\text { dependent) }\end{array}$ \\
\hline${ }^{14} N(n, p){ }^{14} C$ & 2.7 \\
\hline$H\left(n, n^{\prime}\right) p$ & $5.0 \pm 1.0^{*}$ \\
\hline $\begin{array}{l}{ }^{10} \mathrm{~B}(\mathrm{n}, a)^{7} \mathrm{Li} \text { (vasculature) } \\
\text { - Skin necrosis } \\
\text { - CNS necrosis }\end{array}$ & $\begin{array}{l}0.4 \pm 0.2 \\
0.5 \pm 0.2 \\
0.3 \pm 0.2\end{array}$ \\
\hline $\begin{array}{l}{ }^{10} \mathrm{~B} \text { uniformly distributed } \\
\text { (cell culture studies) }\end{array}$ & $\sim 2.3$ \\
\hline
\end{tabular}

Because of the mixed field irradiation and the dramatically varying RBE values involved, there is no basis to anticipate linear response variation with blood-boron concentrations (shown as a linear relationship in Figure 1 for lack of 


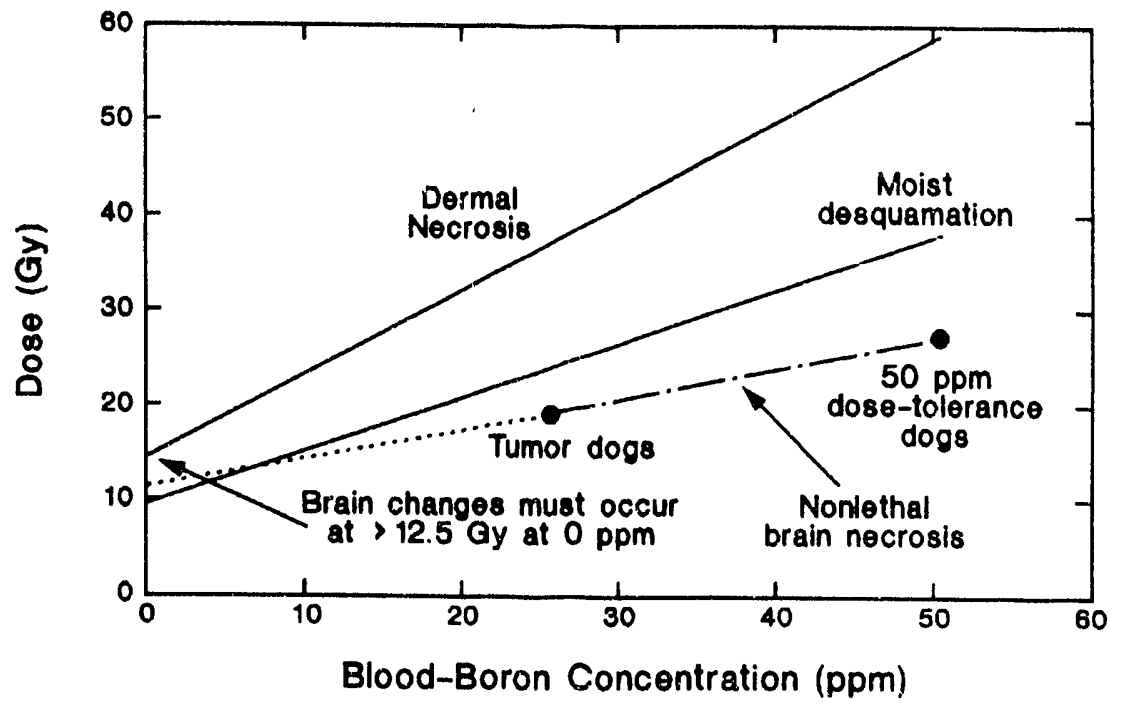

Figure 1. Healthy tissue complications in dogs vs blood-boron and physical dose.

better information). Maximum tolerable tumor dose and optimum tumor control is anticipated to be the result of neutron irradiation with maximized boron concentrations, which appears from available data to be in the range of $100 \mathrm{ppm}$ for BSH. To improve RBE refinement and to establish CNS tolerance at $100 \mathrm{ppm}$ blood-boron concentration, further canine dose CNS tolerance studies are in progress at 0,25 , and $100 \mathrm{ppm}$. It appears that CNS tolerance assessment without boron present will require surgical scalp reflection.

Very large microdosimetric inhomogeneities postulated for the various boron delivery agents dictate caution in presupposing the limiiing normal-tissue-cell population and resulting lesion characteristics including latency. The short boron-fission-fragment track ranges, and evidence that BSH is confined to the lumen volume within normal-brain, suggest that vascular endothelium will limit tolerance. This hypothesis is supported by canine irradiation-response observations. The University of Rochester (UofR) is conducting cellular response studies of rat-brain to verify this hypothesis and confirm that the boron capture lesion is similar to the single-dose, $x$-ray lesion for which response is well established and predistable with a precision acceptable to the medical community. UofR researchers are also verifying early predictors of latent injury onset, and testing the hypothesis that the latent injury, once detected by early indications, can be interdicted by fetal tissue transplant.

\section{Boron Delivery Vehicle Development and} Screening

Boron delivery vehicle development and screening is proceeding with:

1. Boronated hormone release messengers with potential for treatment of pituitary tumors and hormone dependent tumors [Oregon Health Sciences University (OHSU)]

2. Carboranyl alanine and boronated lowdensity lipoproteins (LDL) with potential treatment of met istatic malignant melanoma [University' of California at San Francisco (UCSF)]

3. Boronated liposomes with potential for treatment of metastatic malignant mela- 
noma and mammary sarcoma [University of California at Los Angeles (UCLA)].

The following sections are the reports from the various investigators about their current research.

\section{BORON DRUG DEVELOPMENT}

\section{Carboranyl Alanine and LDL Development and Evaluation}

A second batch of boronated LDL has been prepared by UCSF researchers and sent to the INEL for inductively coupled plasma-atomic emission spectroscopy (ICP-AES) boron measurement. This batch completes the planned series of alkyl and aryl carborane incorporations into LDL. Assuming that boron content of these species is found reproducible and accurate by ICP-AES, and these values are found to match those obtained using prompt gamma techniques, elaidyl carborane carboxylate (ECC) -loaded LDL for animal localization experiments will be prepared. Protein analysis of this most recent batch were in accord with previous batches arid followed similar trends with regard to the carborane encapsulated. A small potential problem has been discovered, however, in the protein standard used for developing the absorption reference standard curve to which samples are compared to obtain their protein content. This material is supplied by the Sigma Company and is labeled as being $5 \mathrm{mg}$ LDL protein per $\mathrm{mL}$ solution. This is actually a minimum value and can be as high as $6.5 \mathrm{mg}$ $\mathrm{LDL} / \mathrm{mL}$. Sigma has agreed to supply accurate individual lot analyses in the future. Although some of the previous batches are internally consistent and do indeed allow observation of general trends of protein content, this observation means that the boron-to-protein ratios are not comparable from batch to batch. This observation also explains, in part, some of the batch-to-batch variation previously observed.

Prompt gamma analyses have been received from Bronkhaven National Laboratories (BNL) for a recent set of 48 LDL samples reconstituted with various alkyl and aryl carboranes and ECC. This series of samples consisted of two sets of 24 each, one set having been "double filtered" through a 0.45 micron filter to determine whether this process would selectively remove aggregated material. Table 1 displays the $\mu \mathrm{g}{ }^{\mathrm{n}} \mathrm{B} / \mu \mathrm{g}$ protein ratios for the six com- pounds evaluated with each value representing four samples. Several observations may be made regarding these values. The singly filtered samples all have ratios within experimental error of ratios for these compounds reported previously with the single exception of 1 -allyl carborane which usually has a large standard deviation. These numbers confirm previous assertion that only 1 -hexyl-and, perhaps, 1 -allyl carborane are viable candidates among the alkyl and aryl for LDL insertion for tumor-boron delivery.

ECC has been the standard for all previous in vitro work, and the blood-to-protein ratio reported here is consistent with values for a number of previous samples used in cell cultures. It is also clear from these data that a second filtration step has a relatively minor effect on the overall blood-to-protein ratio of the boronated LDL. Indeed, in each of the pairs of ratios, both values are within experimental error of each other. However, the raw data (not shown) indicate an interesting effect. For the better reconstituting compounds (hexyl, allyl and ECCl, the absolute boron content is reduced by approximately $10 \%$ during the second filtration, and in each case, so, too, is the absolute protein content. However, for less good reconstituters (methyl, butenyl, and phenyll, the change in boron content varies widely while the protein content decreases by $10-15 \%$. This is further confirmation that these compounds are unsuitable for LDL incorporation and disrupt the LDL in an as yet unknown fashion. ICP-AES boron concentrations for these samples is pending, so that the second goal of this experiment can be obtained, viz do both methods agree within error as to absolute boron content. Nevertheless, researchers conclude from these data that animal experiments may now begin utilizing either 1-hexyl carborane or ECC as the source of boron. A new batch of ECC-loaded LDL is now being prepared for this purpose, and will be sent to Washington State University (WSU) in May.

The back-ordered chiral high-performance liquid chromatography (HPLC) column has arrived at UCSF, and work has recently focused on installing the new column and pioneering separation schemes. Researchers have succeeded in obtaining baseline separation of the $R R$, RS, SR and SS diastereomers and enantiomers of the Mosher's amides of the 
Table 1. LDL Reconstitutions (Batch LW-1-19).

\begin{tabular}{lcc}
\hline \multirow{2}{*}{ Compound } & \multicolumn{2}{c}{$\mu \mathrm{g} \mathrm{n} / \mu \mathrm{g}$ Protein } \\
\cline { 2 - 3 } & Single Filtered & Double Filtered \\
\hline 1-hexyl carborane & $0.71 \pm 0.05$ & $0.68 \pm 0.04$ \\
1-allyl carborane & $0.34 \pm 0.10$ & $0.30 \pm 0.04$ \\
ECC & $0.25 \pm 0.02$ & $0.22 \pm 0.02$ \\
1-methyl carborane & $0.21 \pm 0.05$ & $0.39 \pm 0.15$ \\
1-phenyl carborane & $0.15 \pm 0.05$ & $0.14 \pm 0.04$ \\
1-butenyl carborane & $0.06 \pm 0.02$ & $0.09 \pm 0.03$ \\
\hline
\end{tabular}

benzyl ester of carboranylalanine. It may be recalled that neither the ${ }^{19} \mathrm{~F}$ nuclear magnetic resonance (NMR) spectra of these amides, nor the optical rotations of the free amino acids was adequate to demonstrate optical purity. It now appears that researchers were correct in assertion that both the $D$ and $L$ forms of carboranylalanine can be prepared in at least 95\% enantiomeric excess, at least in $\mathrm{mg}$ quantity. Researchers are now using the chiral column to stepwise check along the intermediates of the pathway to confirm their optical purity, and expect to have some quantitative results during May 1992.

\section{Boronated Liposome Development and Evalua-} tion

Liposome Encapsulation and Development: Murine melanoma screening experiments with liposomes containing $\left(\mathrm{B}_{20} \mathrm{H}_{17} \mathrm{NH}_{3}{ }^{3}\right)$, $\left(\mathrm{B}_{10} \mathrm{H}_{8} \mathrm{NCO}\right)^{20}$, and $\left(\mathrm{Co}\left(\mathrm{C}_{2} \mathrm{~B}_{8} \mathrm{H}_{10} \mathrm{SH}\right)_{2}{ }^{2}{ }^{1}\right.$ have been completed at WSU. A liposomal sample of $\left\{\mathrm{B}_{20} \mathrm{H}_{1} \mathrm{OH}\right\}^{4 \cdot}$ has been prepared by UCLA researchers and a murine experiment is in progress. Screening experiments utilizing the EMT6 tumor line at Vestar, Inc. have been completed with liposomes containing $\left(\mathrm{B}_{10} \mathrm{H}_{9} \mathrm{NCO}\right)^{2}$ and $\left(\mathrm{B}_{20} \mathrm{H}_{1}, \mathrm{NH}_{3}\right)^{3 .}$. All murine samples are at the INEL for boron analysis.

The isocyanate derivative of decahydrodecaborate(2-), $\left(\mathrm{B}_{10} \mathrm{H}_{8} \mathrm{NCO}\right)^{2}$, has been of interest because of its potential to react with intracellular proteins. This species has been encapsulated in liposomes at UCLA and sent to WSU for murine screening. Another borane anion with potential for protein-residue reactivity,
$\left(\mathrm{C}_{2} \mathrm{~B}_{9} \mathrm{H}_{10} \mathrm{SH}\right)_{2} \mathrm{Co}^{\prime}$, has been prepared and its conversion to a water-soluble form is in progress.

The $\left[\mathrm{Co}\left(\mathrm{C}_{2} \mathrm{~B}_{8} \mathrm{H}_{10} \mathrm{~S}\right)_{2}\right]^{1 \cdot}$ anion, a disulfide complex with the potential of reacting with intracellular proteins, has been prepared and its conversion to a water soluble form is imminent. Scheduling with both WSU and Vestar, Inc. is in progress.

Liposomes doped with $n$-hexylcarborane, ranging in the amount of boron from $1 \%$ to $6 \%$ of the lipid mass, have been synthesized. Boron analysis of the liposomal suspensions should distinguish between liposomal encapsulation and membrane embedment. A longer chain on the carborane cage, such as a $C_{18}$ chain or a $\mathrm{C}_{18}$ chain, should be more usefu! in aligning the boron compound in the membrane and, therefore, stabilizing the liposomal membrane. $n$-Hexadecylcarborane is currently being synthesized for this purpose.

The liposomes used in this project have previously been shown to be very stable in simple aqueous buffer solutions over a long period of time. Attempts have been made to determine the stability of the liposomes by ultracentrifugation from fetal bovine serum at $37^{\circ} \mathrm{C}$. Initial experiments suggested that the liposomes were extremely stable in serum (>95\% intact) after 16 hours. However, two control experiments of the free (nonencapsulated) compounds indicated that the borane anions used $\mathrm{B}_{20} \mathrm{H}_{18}{ }^{3}$, $n-\mathrm{B}_{20} \mathrm{H}_{18}{ }^{2}$, and $\left.\mathrm{B}_{20} \mathrm{H}_{17}, \mathrm{OH}^{4}\right)$ are bound to serum proteins to a significant degree $(30-60 \%)$. This is believed to be a result of a nonspecific 
interaction between the borane anion and serum proteins. Consequently, the vesicle serum stability data cannot be quantified, since the boron compounds retained could either be bound to protein or within intact liposomes. Further experiments are being designed to differentiate free borane salts, encapsulated borane, and protein-bound borane.

Compound Development: The synthesis of lipophilic boron compounds for embedment in the liposome bilayer has been investigated. Small quantities of such compounds incorporated into the lipid membrane may significantly increase the boron content carried by the liposome. Initial studies have been focussed on Jerivatives of the icosahedral closo- $\mathrm{C}_{2} \mathrm{~B}_{10} \mathrm{H}_{12}$. Substitution at a carbon atom with a $n$-octyl group has produced $\mathrm{C}_{18} \mathrm{H}_{37}\left(\mathrm{C}_{2} \mathrm{~B}_{10} \mathrm{H}_{11}\right)$. A similar reaction starting with carboranyl ethanol has produced an ether derivative, $\mathrm{C}_{18} \mathrm{H}_{37} \mathrm{OCH}_{2}\left(\mathrm{C}_{2} \mathrm{~B}_{10} \mathrm{H}_{11}\right)$. These compounds are designed to be lipophilic with long carbon chains to facilitate their packing in the lipid membrane. The carborane cage in either compound may be reduced to a mono-anionic, nine-boron cage, which also may assist in the boron compound's alignment within the membrane.

Octadecyne, $\mathrm{CH}_{3}\left(\mathrm{CH}_{2}\right)_{15} \mathrm{C}=\mathrm{CH}$, can be purchased from Alfa Chemicals. This compound can be reacted with decaborane, $\mathrm{B}_{10} \mathrm{H}_{14}$, directIy to form a $n$-hexadecyl substituted ortho-carborane. The resulting compound can be degraded to a mono-anionic, nine-boron cage, which may assist in the boron compound's alignment within the membrane. The $n$-hexadecylcarborane has been synthesized and purification is in progress.

Thus far, researchers have synthesized three compounds in a cobalt complex series for encapsulation into liposomes: $\left[\mathrm{Co}\left(\mathrm{C}_{2} \mathrm{~B}_{8} \mathrm{H}_{1,}\right)_{2}\right]^{1}$, $\left[\mathrm{Co}\left(\mathrm{C}_{2} \mathrm{~B}_{8} \mathrm{H}_{10} \mathrm{SH}\right)_{2}\right]^{1 .}$, and $\left[\mathrm{Co}\left(\mathrm{C}_{2} \mathrm{~B}_{9} \mathrm{H}_{10} \mathrm{~S}\right)_{2}\right]^{1 .}$. The final compound in the series, the disulfide monoxide, $\left[\mathrm{Co}\left(\mathrm{C}_{2} \mathrm{~B}_{9} \mathrm{H}_{10} \mathrm{~S}\right)\left(\mathrm{S}(\mathrm{O}) \mathrm{C}_{2} \mathrm{~B}_{9} \mathrm{H}_{10}\right)\right]^{1 .}$ is being prepared by the oxidation of the disulfide complex.

\section{Pituitary Tumor Evaluation}

Radioimmunoassay (RIA) procedures are being set up by researchers at OHSU for adrenocorticotrophic hormone (ACTH) and growth hormone $(\mathrm{GH})$ from AtT-20 and $\mathrm{GH}-3$ cells, re- spectively, to assess distal cell function of these cells after neutron exposure. Reagents to perform these assays continue to arrive from the National Pituitary Agency (Baltimore, MD).

Resonance ion spectroscopy (RIS) experiments are being carried out Dy researchers at Atom Sciences (Oak Ridge, $7 N$ ) to quantitate carborane standards inoculated into brain tissue. Results from these stijdies will determine if this approach is sensitive enough to measure pituitary boron level's during in vitro and in vivo experiments. OHSU staff have taken AtT-20 cells to the Oregon State University (ORSU) reactor facility for sub-culturing and to provide material for investigators there to perfect aseptic cell handling techniques. A new "neutron exposure vial" has also been delivered to the reactor facility for acceptability testing in the neutron beam.

Systems are being implemented to enable rat pituitary tumor cells to be grown at ORSU, eliminating the transport of these cells from Portland, OR. Early trials of cell viability in the neutron beam will commence in the very near future.

Measuring Dosimetry: ORSU reactor facility staff is continuing to design and test shielding for the stringer port to minimize the background gamma radiation potentially affecting the pituitary tumor cells during neutron exposure. All of the members of the OHSU re search team have taken the orientation course at the ORSU reactor facility and have successfully met all of the facility's requirements, enabling OHSU researchers to work (in conjunction with ORSU staff) at the reactor site on these studies. Pituitary tumor cell exposures will begin in the very near future.

\section{BORON LOCALIZATION SCREENING}

\section{Boronophenylalanine (BPA) Evaluation Studies}

Biodistribution of BPA: A second study investigating the effect of limiting tyrosine and phenylalanine in the diet of tumor-bearing mice was conducted by researchers at WSU. The tissues are awaiting analysis by INEL. In addition, routes of administration of BPA were investigated. Mice were injected with BPA either intraperitoneally $(750 \mathrm{mg} / \mathrm{kg})$ or intrave- 
nously $(1 \mathrm{mg} / \mathrm{mL})$, and tissue samples were taken at 6 and 12 hours postinjection. The tissues were sent to the INEL for analysis.

BPA Dese-Response Curve: Experiments have shown uptake of p-BPA by BL 6 cells cultured in vitro, in normal medium, increased in a dosedependent manner. Cellular boron levels increased from $0.494 \mu \mathrm{g}$ boron/g wet cells at the $25 \mathrm{mg}$ p-BPA/L medium level to $0.932 \mu \mathrm{g}$ boron $/ \mathrm{g}$ wet cells at the $100 \mathrm{mg} \mathrm{p}-\mathrm{BPA} / \mathrm{L}$ medium level. In phenylalanine/tyrosine restricted medium (4/4 medium), p-BPA uptake by BL6 cells cultured in vitro also increased in a dose-dependent manner. However, in the $4 / 4$ medium, BL6 cells exhibited a much greater cellular uptake of P-BPA than BL6 cells cultured in normal medium. At the $25 \mathrm{mg} \mathrm{p}-\mathrm{BPA} / \mathrm{L}$ medium level in 4/4 medium BL6, p-BPA uptake was $1.748 \mu \mathrm{g}$ boron/g wet cells, and $7.0 \mu \mathrm{g}$ boron $/ \mathrm{g}$ wet cells at the $100 \mathrm{mg} \mathrm{p}-\mathrm{BPA} / \mathrm{L}$ medium level. BL6 cells, cultured in low phenylalanine/tyrosine medium, exhibited an increased $p$ BPA uptake of 3.5, 4.54, 8.02, and 7.5 times, at the $25,50,75$, and $100 \mathrm{mg}$ p-BPA/L medium levels, respectively, as compared to BL.6 cells cultured in normal medium (see Figure 2).

Miscellaneous: A study to investigate the use of phenylalanine ammonia lyase (PAL) to increase the uptake of BPA is underway. The initial step involves an enzyme assay to determine whether BPA is enzymatically degraded by PAL. The assay is being conducted under the following conditions: $8.33 \times 10^{4} \mathrm{M} \mathrm{L}$ phenylalanine or $8.33 \times 10^{.4} \mathrm{M}$ BPA, $1 \times 10^{-1} \mathrm{M}$

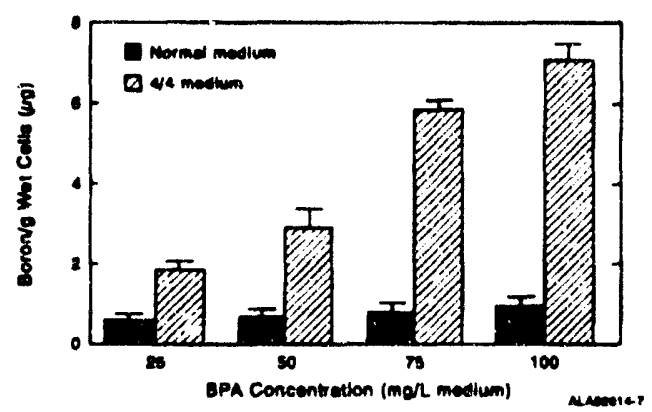

Figure 2. Low levels of Phenylalanine and tyrosine enhance BL6 cellular boron uptake.
Tris-HCL, pH 8.5, and enzyme 1.021 units of $P A L)$ in a volume of $3.0 \mathrm{~mL}$ incubated at $30^{\circ} \mathrm{C}$. The appearance of cinnamic acid is measured by the increase in optical density at $290 \mathrm{~nm}$ (Zucker, 1965). Subsequent in vitro experiments will be based on these results. In vivo experiments will follow.

\section{Liposome Evaluation Studies}

CMPD3A-157 $\left(\mathrm{K}_{4} \mathrm{~B}_{20} \mathrm{H}_{17} \mathrm{OH}\right):$ The administration of this liposomal encapsulated boron compound was repeated in tumor-bearing mice. Tumor size and macrophage blockage by empty liposomes were varied in order to compare to preliminary data obtained from this compound in October 1991. An empty liposomal compound was administered intravenously to one group of mice approximately $\mathbf{3 0}$ minutes prior to boron encapsulated liposome administration. Tissues were taken through time and sent to INEL for boron analysis.

CMPD4B-221, CMPD6-34-2, CMPD7-51-2, and CMPD8-82-2: Tissues are awaiting analysis at INEL.

An in vitro study investigating the effects of boron encapsulated liposomes on tumor cell growth has been completed. Preliminary data show little difference in growth or viable cell numbers:

Control Boron/Liposomes
(live/dead)

\begin{tabular}{|c|c|c|}
\hline Cell No. & $\begin{array}{c}10.7 \times 10^{8} / \\
1.1 \times 10^{6}\end{array}$ & $\begin{array}{l}9.0 \times 10^{6} / \\
2.5 \times 10^{6}\end{array}$ \\
\hline II & $0.08 \mathrm{~g}$ & $0.07 \mathrm{~g}$ \\
\hline
\end{tabular}

CMPD8-102-2 $\left(\mathrm{NaLCO}\left(\mathrm{C}_{2} \mathrm{~B}_{9} \mathrm{H}_{10} \mathrm{SH}\right)_{2}\right)$ : Screening of this compound was completed April 10, 1992. Tissues are awaiting analysis at INEL.

The ninth boron screening began the week of April 18, 1992. Mice were first injected with tumor and then were injected with a boron-encapsulated liposome on April 27, 1992. 


\section{DR U G S T A B I L I T Y, PHARMACOLOGY AND TOXICITY}

\section{Toxicological Evaluation of BSH}

Earlier Idaho State University (ISU) researchers reported selected aspects of research on the toxicity and evaluation of BSH effects on cardiac output, stroke output, left ventricular pressure, arterial pressure, central venous pressure, heart rate, electrocardiogram (EKG). respiratory rate, and tidal volume. A summary of key findings is presented this month. Key findings to date must still be regarded as tentative because $N$ values are small lone to three animals per point). Researchers' current view of the cardiovascular toxicity of BSH can be summarized as follows:

1. Intravenous (IV) infusion of BSH at a volume rate of $283.3 \mathrm{uL} / \mathrm{kg} / \mathrm{min}$ and a dose rate of $28.33 \mathrm{mg} / \mathrm{kg} / \mathrm{min}$ elicited marked aberrations in cardiovascular function and, less frequently, changes in respiratory function.

A. Infusion of $750,500,375$, and $250 \mathrm{mg} / \mathrm{kg}$ BSH resulted in cardiovascular collapse, respiratory depression, and death within six hours of infusion. The higher the dose, the faster the onset of cardiovascular collapse and death.

B. Infusion of $150 \mathrm{mg} / \mathrm{kg}$ BSH did not appear to be toxic, but the post-observation period was short (one hour).

2. Bolus IV injection of BSH lover a two-minute period) elicited responses qualitatively similar to those of IV infusion. Effects were usually quicker in onset and of greater magnitude than those elicited by infusion. Respiratory abnormalities were more pronounced after bolus IV injection.

A. Bolus injection of 200 and $375 \mathrm{mg} / \mathrm{kg}$ were lethal in instrumented animals. The sole noninstrumented rat injected with BSH $(200 \mathrm{mg} / \mathrm{kg})$ survived, sug. gesting that the process of instrumenting rats for recording of cardiovascular and respiratory function might render the animals more sensitive to the toxic effects of BSH.

3. IV infusion of vehicle $10.1 \mathrm{M}, \mathrm{pH} 7.4$ phosphate buffer) to an instrumented rat at the same volume rate $(283.3 \mathrm{~mL} / \mathrm{kg} / \mathrm{min})$ did not elicit changes in cardiovascular or respiratory function.

4. Bolus IV injection of a glucose load whose osmolarity was equivalent to that of $375 \mathrm{mg} / \mathrm{kg}$ BSH was not lethal. This injection did elicit a transient (five-minute) elevation of arterial blood pressure and left ventricular pressure, but did not alter respiratory rate, tidal volume, heart rate, EKG pattern, or central venous pressure. The elevation of blood pressure and left ventricular pressure were loss than that observed after bolus in: cition of 200 $\mathrm{mg} / \mathrm{kg} \mathrm{BSH}$.

5. IV infusion of BSH resulted in an extremely rapid rise in arterial pulsatile blood pressure, mean arterial pressure, left ventricular pressure, and stroke output. These changes persisted for at least 15 minutes, and usually longer. Usually, but not always, respiratory rate and tidal volume remained unchanged. Central venous pressure was sometimes slightly increased, but large changes in central venous pressure were not observed. Heart rate and cardiac output mostly remained stable or initially increased very slightly. Over time, cardiac output, stroke output, left ventricular pressure, and mean arterial pressure exhibited a gradual but marked decline. This gradual decline usually was interrupted by a sudden period of abnormal EKG activity immediately followed by a sharp drop in left ventricular and arterial pressure. The sharp drop in pressure invariably was associated with the death of the animal. In most cases, respiratory rate and tidal volume declined in concert with the cardiovascular parameters.

A. In some experiments, cessation of respiration preceded the collapse of left ventricular and mean arterial pressure. However, death apparently does not result from a failure of central respiratory drive, because artificial respiration failed to prevent the cardiovascular collapse and death associated 
with the IV infusion of $500 \mathrm{mg} / \mathrm{kg}$ BSH.

6. Bolus IV injection of BSH also resulted in a very rapid rise in arterial pulsatile blood pressure, mean arterial pressure, and left ventricular pressure. These changes were more pronounced than the changes observed with IV infusion of BSH. IV injection of $375 \mathrm{mg} / \mathrm{kg}$ BSH rapidly suppressed the electrical activity of the heart, suggesting a possible direct toxic action on the heart at high doses. Bolus injection also revealed an abnormal breathing pattern: bursts of increased respiratory activity associated with elevated tidal volumes were interspersed with bouts of slower, lower respiration.

A. BSH induced changes in respiratory function may be dissociable from BSHinduced changes in cardiovascular function, suggesting that BSH may be affecting central respiratory control pathways independent of any effect on central cardiovascular control pathways.

Summary: BSH appears to be capable of eliciting cardiovascular collapse and death at infusion rates only slightly greater $(2.5 x)$ than those being used in the dog studies. Researchers are currently evaluating whether the process of instrumenting rats makes them more susceptible to the toxic effects of BSH. Literature reports suggest that BSH is a safe compound possessing few toxic iide effects. ISU research data suggest that this view may not be warranted and that people may be confusing lack of evidence about toxic effects with evidence of a lack of toxic effect. Further studies are needed to determine if BSH infusions represent significant risk to humans.

Again, ISU researchers stress that the above statements are not firm conclusions, but only possibilities. The limited number of experiments conducted to-date only allow conclusion that BSH can interfere with cardiovascular and respiratory function. All else represents working hypotheses.

\section{Toxicological Evaluation of BPA}

ISU researchers have also been evaluating the effects of BPA on arterial pressure, heart rate,
EKG, respiratory rate, and tidal volume. To characterize acute toxic reactions associated with IV overdose of BPA, one must first identi$f y$ an acute lethal dose. This has proven to be difficult because BPA is poorly soluble in most aqueous formulations, making it difficult to deliver iznough drug via the IV route t() create an acute toxic episode. In a previous report, researchers indicated that $100 \mathrm{mg} / \mathrm{kg} \mathrm{BPA}$ $16 \mathrm{mg} / \mathrm{mL}$ solution administered at a rate of $17 \mathrm{~mL} / \mathrm{kg} / \mathrm{hr}$ ), infused IV over a one-hour timespan into urethane anesthetized rats, did not consistently elicit treatment related chang. es in either heart rate or arterial blood pressure. However, this dose of BPA did occasionally olicit changes in cardiac output, stroke output, and blood pressure (results summarized in the January 1992 report). Researchers also found that higher doses of a BPA-diethanolamine (BPA-DEA) formulation $(425 \mathrm{mg} / \mathrm{kg}$ delivered over one hour) elevated blood pressure, but until recently, researchers have been unable to deliver concentrations of BPA sufficient to cause an acute lethal response. For the last few months, researchers have been exploring the work of Yoshino, et al. (Strahlentherapie und Onkologie, 165:127). These authors reported that $30 \mathrm{mg} / \mathrm{mL}$ solutions of BPA could be produced by complexing BPA with fructose.

Using this approach, ISU researchers have prepared $\mathrm{pH} 7.4$ aqueous solutions containing approximately $166 \mathrm{mg} \mathrm{BPA} / \mathrm{mL}$. This solution was infused (IV) to anesthetized rats at delivery rates of $8.5,12.8$, and $17 \mathrm{~mL} / \mathrm{kg} / \mathrm{hr}$, and thereby delivered $1,411,2,125$, and 2,822 $\mathrm{mg} / \mathrm{kg}$ BPA over a one-hour infusion period. To maintain osmotic balance, BPA infusions were followed by a 30-minute infusion of quarter normal saline. Animals infused with vehicle (fructose in BPA) survive these treatment regimens without apparent problem. Five rats have received IV infusions of $2,125 \mathrm{mg} / \mathrm{kg}$ BPA $(12.8 \mathrm{~mL} / \mathrm{kg} / \mathrm{hr})$. Depending on the extent of instrumentation, these rats were observed for either 6 or 48 hours. This infusion rate seems to be relatively nontoxic, although hematuria (bloody urine) was routinely observed and one rat did die five hours postinfusion. However, since blood samples were being repeatedly drawn to monitor blood-boron concentrations, the added stress of repeated blood collections may have contributed to the death. Rats infused with $2,125 \mathrm{mg} / \mathrm{kg}$ BPA and not instrumented or sampled displayed no grossly obvious impairment of function. Gross and histo- 
pathological examinations are scheduled to assess if organ damage is occurring. Five rats have also been infused at a rate of $17 \mathrm{~mL} / \mathrm{kg} / \mathrm{hr}$ $(2,822 \mathrm{mg} / \mathrm{kg}$ over a one-hour infusion period). Two rats instrumented for recording of cardiovascular and respiratory parameters died within six hours of infusion. Three rats infused with $2,822 \mathrm{mg} / \mathrm{kg} \mathrm{BPA}$, but not instrumented, were observed for seven days. One of the three rats died within six hours of infusion. The other two animals were sacrificed at seven days and tissues collected for histopathology. A single rat infused at a rate of $8.5 \mathrm{~mL} / \mathrm{kg} / \mathrm{hr}$ $(1,411 \mathrm{mg} / \mathrm{kg})$ displayed no alterations in cardiovascular or respiratory function, suggesting that the previous cardiovascular alterations obtained with the BPA-DEA formulation may reflect the combined effects of BPA and DEA rather than the effect of BPA alone.

Summary: ISU researchers' current view is that BPA appears to be a relatively nontoxic drug and on a $\mathrm{mg} / \mathrm{kg}$ basis appears to be safer than BSH. Researchers aie pleased that they have finally found a means of cielivering a lethal IV dose of BPA to rats, since this means that they can now proceed to identify the limiting toxicity. Investigations are underway to define the mechanisms underlying the lethal response, as are biodistribution studies to evaluate blood, tissue and urine levels of boron after large IV doses of BPA.

\section{Drug Interaction Studies}

Early protein binding work, performed by INEL BNCT Research Program researchers, has suggested that BSH binds differently to human serum albumin (HSA) than to bovine serum albumin (BSA). Binding was also observed to be influenced by temperature with decreasing binding as temperatures increased from ambient to physiological values. These early experiments were performed at BSH concentrations (100-200 ppm boron) in the range of concentrations measured in canine kinetic studies. Recent canine experiments by WSU researchers at dose levels of $100 \mathrm{mg} / \mathrm{kg}$ boron have resulted in immediate death to three animals. This suggested a potential $\mathrm{BSH}$-anesthetic interactive toxicity and prompted the use of much higher BSH concentrations in the ongoing in vitro protein binding studies. Equilibrium dialysis experiments were set up by ISU researchers to observe BSH concentrations from 500-2500 $\mu \mathrm{g} / \mathrm{mL}$ (corresponding to approximately 370 -
$1490 \mathrm{ppm}$ of boron). All experiments were run for two hours at $37^{\circ} \mathrm{C}$ and the free fraction of BSH measured. Figure 3 shows that at very high BSH concentrations, the binding characteristics of BSH to either HSA or BSA actually becomes smaller. Mechanistically, this is difficult to explain at this time, although other work by BNCT researchers has indicated that tertiary protein structure may actually be disrupted at high BSH concentrations. Work is currently progressing to determine how canine serum albumin reacts relative to HSA and BSA. Other ongoing equilibrium dialysis experiments to observe the ability of BSH to displace phenobarbital, or other coadministered drugs, have not been reproducible to date. Even more puzzling were results indicating higher BSH concentrations than were initiallv added to the cells. One of the significant findings possibly contributing to this variance was the discovery of an unknown component that leaches from dialysis membranes using conventional aqueous conditioning iechniques and absorbs in the low ultraviolet range. This is significant, since BSH is monitored at a lower wavelength spectrophotometric (207 nmeters) for multicomponent analysis. The interference could be reduced, but not eliminated, by conditioning mambranes overnight in a $60 \%$ ethanol solution. Investigations are now underway to determine if a secondary wavelength may be useful.

Alternatively, researchers have begun to measure BSH concentrations using Fourier Transform Infrared Spectroscopy (FTIR). Figure 4 shows a standard curve for $\mathrm{BSH}$ over the range of $50-500 \mu \mathrm{g} / \mathrm{mL}$ in the presence of $40 \mu \mathrm{g} / \mathrm{mL}$ phenobarbital. Quantitating even higher BSH levels should present no problems. There is no

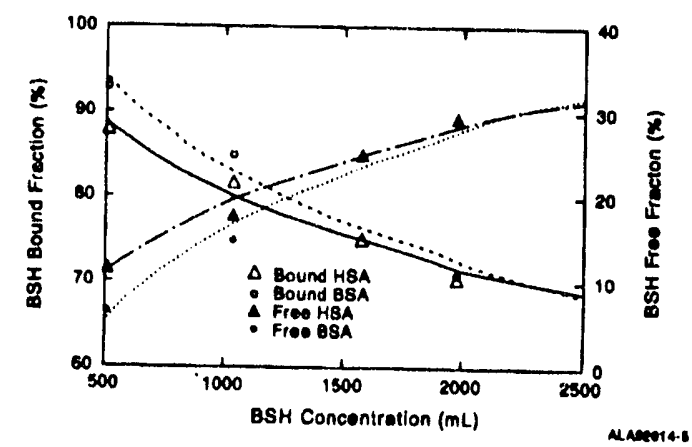

Figure 3. Equilibrium dialysis binding curves in $0.5 \mathrm{~mL}$ protein. 


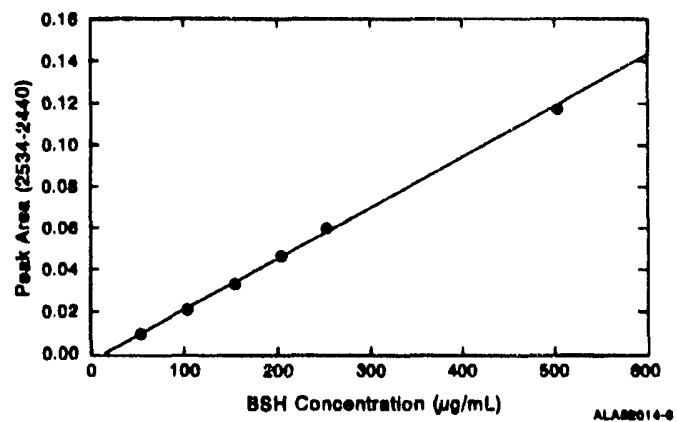

Figure 4. FTIR standard curve for BSH in the presence of $40, g / \mathrm{gL}$ phenobarbital.

interference from either phenobarbital or proteins at wave numbers 2534-2440, a region where BSH shows a strong band. Although this technique is somewhat more tedious than multicomponent ultraviolet analysis, it may yet turn out to be the most useful method to simultaneously quantitate multiple drugs in the reaction mixture.

Finally, experiments are just beginning to more carefully define the binding characteristics of BSH through a more traditional determination of total, nonspecific, and specific binding. Rather than radiolabeled experiments, however, advantage is being made of the isotopic differences in ${ }^{10} \mathrm{~B}$ and ${ }^{11} \mathrm{~B}$, as well as the stable isotopes for some of the potentially displaced drugs of interest. These experiments will use the naturally-occurring isotopic form as the cold ligand and the less common isotope as the labeled drug to perform binding and displacement experiments. The differences in the two isotopic forms will be quantitated using mass spectroscopic techniques. Preliminary work has begun using the technique with the stable isotope of theophylline to measure protein binding. Theophylline was chosen because its stable isotope was already available inhouse, as well as the fact that it demonstrates albumin binding characteristics similar to the drugs of interest. Instrument parameters are being optimized for selected ion monitoring of the compounds and extraction techniques are being validated to extract the drugs of interest from the aqueous medium for subsequent injection onto the instrument.
Work on this task was suspended April 1 , 1992 because it supported human clinical trials and was not deemed essential to drug screening studies. It will be necessary to withdraw a paper on this subject that has been submitted to the Fifth International Symposium on Neutron Capture Therapy.

\section{TREATMENT PROTOCOL DEVELOPMENT}

Large Animal Model Studies

Pharmacckinetics: No additional dogs have been infused.

Normal Tissue Tolerance (Neutron Irradiation): Seven dogs, including three at $50 \mathrm{ppm}$ irradiat ed at $27 \mathrm{~Gy}$, two at $100 \mathrm{ppm}$ irradiated at $27 \mathrm{~Gy}$, and two at 100 pprn irradiated at $31 \mathrm{~Gy}$, received six-month checkups in March 1992. Six dogs, including three at $100 \mathrm{ppm}$ irradiated at $35 \mathrm{~Gy}$ and three at $25 \mathrm{ppm}$ irradiated at $27 \mathrm{~Gy}$, received their six-month checkups in April 1992. Three normal dogs were irradiated in March at BNL. The dogs were at $25 \mathrm{ppm}{ }^{10} \mathrm{~B}$ and irradiated at $19 \mathrm{~Gy}$.

Soontaneously-Occurring Brain Tumor Dogs: "Dudley" Fiset (\$35447-151), a six-year old, castrated male Golden Retriever, had his oneyear checkup at University of California/Davis and he has been determined to be clinically normal. The scans did not reveal any tumor. "Dudley" is doing great and is down to 110 pounds.

"Muffy" Lower ( $\$ 35447-140$ ), a four-year old, spayed female Terrier cross, had her right eye removed by her local veterinarian in March 1992. The eye was removed because of chronic keratonconjunctivities sicca (KCS) and had been nonresponsive to medication. The KCS may have been secondary to nerve damage from her tumor. "Muffy" recovered from the surgery and is compensating for the loss of her eye. An episode of bloody diarrhea and vomiting has cleared up.

"Brandy" Hoff (\#35447-94), a seven-year old, spayed female Golden Retriever, is doing great. "Brandy" will be returning to WSU for her two and a half year checkup in May 1992. 


\section{Physiological Response Evaluation and Interdiction}

Forebrain Irradiation Model: Male Long Evans rats (200-250 g) were irradiated in February 1992 by UofR researchers using a Picker C8 cobalt source. Radiation exposure was limited to $30 \mathrm{~Gy} / \mathrm{hemisphere} \mathrm{for} \mathrm{a} \mathrm{tntal} \mathrm{dose} \mathrm{of} 60 \mathrm{~Gy}$. A Lexan stereotaxic frame was used in conjunction with a collimator to restrict the exposure to an area described by an inverted triangle between the eyes and ears. Animals are scheduled to be sacrificed at 2, 6, 12, and 24 weeks postirradiation. Five animals in each group will be treated with Horse Radish Peroxidase (HRP) IV 10 minutes prior to sacrifice to evaluate deterioration of the blood-brain-barrier. An additional three animals per time point will be injected using a fixative that is acceptable for light microscopy (LM), as well as electron microscopy (EM). Following perfusion, the brains will be removed and sectioned at $75 \mu \mathrm{m}$ using a vibratome. HRP-treated tissue sections will be processed for $L M$ and EM to study vascular damage. Non-HRP-treated brains will be processed for EM analysis of myelin and vascular integrity. Analyses will involve vascular density counts, examination of cortical thickness and area of blood-brain-barrier leaks.

To date, all two-week postirradiation animals have been processed and analyzed. Analysis is virtually complete on all other time points. Initially, analysis was limited to the cortex and corpus callosum. Upon further evaluation, it was decided to expand the study to include the hippocampus and fimbria. The study of these structures is currently underway. Analyses have indicated that by 24 weeks postirradiation several statistically significant changes have occurred. First, a decrease in vascular density of $15-20 \%$ was observ'sd in both the cortex and corpus callosum. A similar decrease in cortical thickness was also observed. The most dramatic change noted to date is the relative area of blciod-brain-barrier leakage in the cortex, corpus callosum, hippocampus, and fimbria. The increase in blood-brain-barrier leakage area increased from five- to ten-fold from the control animals in 24 weeks. It should be noted that while there were changes observed in the 2-,6-, and 12-week postirradiation groups, they were not as dramatic as those noted in the analysis of the 24-week animals. Based on initial analysis, the significant changes would appear to occur between the 12- and 24-week time points. Upon termination of this task, researchers will be able to analyze irradiated animals at 18 weelks posttreatment.

Fetal Grafts into Irradiated Forebrain: Male Long Evans rats (200-250 g) received $60 \mathrm{~Gy}$ radiation using the procedure described above. The following experimental groups were created with 12 rats per group: (a) control (nonirradiated, nonoperated), (b) $60 \mathrm{~Gy}$ irradiated (nonoperated), (c) $60 \mathrm{~Gy}$ irradiated-sham transplant, and (d) $60 \mathrm{~Gy}$ irradiated-fettal transplant. Five to six days postirradiation rats in the sham and transplant groups received implants. The sham group received saline and the transplant animals received embryonic-day- 15 rat-fetal cortical grafts. Each animal received a total of six implants (two at each of three sites) into the cortex and corpus callosum. Following treatment, the animals were weighed on a weekly basis and visually inspected on a daily basis. The analysis will be identical to the forebrain irradiation model with the additional analysis of graft survival and vasculature.

This experiment is in progress and is scheduled to terminate at 18 weeks postop. A computer database of animal weights and health status is currently under preparation. A minimum of five animals per group is considered necessary for statistical analysis. To date, the sham and transplant groups have experienced a $25 \%$ mortality rate. One animal from each group died within two weeks of surgery. This could possibly be attributed to brain edema resulting from radiation exposure. The remaining deaths could be attributed to aneurysms or other vascular failure. Two animals were recently sacrificed for failure to thrive based on weight loss and/or general physical condition. These animals exhibited a noticeable degree of hydrocephalus. One should note that the only deaths have occurred in these two groups. No losses or physical impairment have been observed in the control and 60-Gy nonoperated groups. The reason for these losses is currentIy under investigation. No conclusive evidence has been found as to the cause of these deaths. The brains of the sacrificed rats are currently being prepared for sectioning. This shoula provide some indication of the mechanism of death. Further investigation into this problem is required before starting another transplant study. The current endpoint of 18 weeks should provide valuable information 


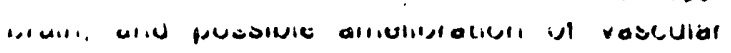
damage resulting from the combination of radiation and physical injury caused by the transplant cannula.

\section{SUPPORTING TECHNOLOGY DEVELOPMENT}

Task 1: Biochemistry BSH and its Oxidation Products

University of Utah (UofU) researchers have begun a high-field, ${ }^{11} \mathrm{~B}, \mathrm{NMR}$,study of the interaction of BSH with HSA. Longitudinal relaxation rates (R1) have been obtained for the four boron types in BSH vs coricentration of HSA. At $21^{\circ} \mathrm{C}$ the rates increase linearly to $3 \%$ albumin and then fall off, indicating saturable interaction. Raising the temperature to $37^{\circ} \mathrm{C}$ decreases these rates, but, apparently, "opens" up new binding sites on the protein since linearity extends to $4 \%$. These results are very similar to those obtained earlier with BSA.

Although comparative albumin binding characteristics are believed to be necessary for extrapolation of animal pharmacokinetic results to anticipated human response, and knowledge of albumin binding characteristics may lead to improved tumor uptake and avoidance of adverse drug interaction response, results from this task are not essential to near-term canine BSH screening studies. Work on this task was therefore suspended at month end because of funding restrictions.

\section{Task 2: Noninvasive Boron Quantification}

Dr. Martin P. Schweizer (UofU) presented this task to the DOE Office of Program Assessment Nuclear Medicine review panel in Los Angeles, CA on April 22, 1992.

UofU: The glioma tumor model project has begun with the inoculation of two Labrador Retrievers. A neurosurgeon at UofU Medical Center performed the inoculation. Progress of the tumors will be monitored by proton magnetic resonance imaging (MRI) daily after one week. Full maturity of tumors is expected within two weeks after inoculation; after which the tumors will be excised and analyzed by pathology. The inoculation results were inconclusive for both dogs because of attendant

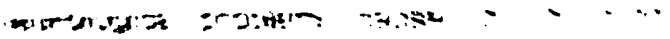

for one, and a potential misplacement of the virus outside the temporal lobe for the other. The misplacement may still result in a tumor and will be monitored by proton imaging for two more weeks. This task will be suspended because MR work at the UofU was directed specifically toward human clinical, pharmacokinetic studies.

Experiments to determine the effective increase in signal-to-noise by doing nonisotropic imaging $(32 \times 32 \times 16)$ with a lower noise preamplifier were performed on phantoms and the results indicate there will be an increase of two over the $32 \times 32 \times 32$ matrix imaging. This was not unexpected as these results were predicted by theory.

Northwest Imaging (NWI): Continuation of the boron imaging project at NWI is on an indefinite hold and agreements between General Electric (GE), NWI, and INEL to perform spectroscopy at NWI are not being pursued.

Task 3: Real-Time Measurement Dosimetry Research

A shield design has been completed for testing feasibility of realtime monitoring of the boroncapture-gamma-rays in boron-infused subjects. A Germanium detector and a plastic phantom (that can be loaded with boron) will be used at the filtered beamport of the BMRR. The Germanium detector shield will use an existing 5$\mathrm{cm}$ thick tungsten shield/collimator that is designed for the detector and it will have an additional $10-\mathrm{cm}$ thick layer of lead around it. It is pla.ined to stack standard $2 \times 4 \times 8$-inch lead bricks around the tungsten for this. Support of the shield will be done using an existing crank-operated lift table. The Brookhaven Reactor Division has been asked to review the plan for materials and floor loading. This task was terminated at midmonth because it was required only to support human clinical trials.

\section{Task 4: Analytical Dosimetry}

Task 4A: Macrodosimetric ModelDevelopment

Further development of the user friendly analytical dosimetry system, suitable for physician use, has been cancelled because INEL physicists can execute near-term calculations re- 
quired to support drug screening studies with the present system. The current version of this module will be archived for future reference. Develop.nent of the medical image reconstruction and display module, in collaboration with Montana State University (MSU), will be suspended after completion of the April 30, 1992, $X$-port milestone. The software will be archived at that point for future reference. It will be necessary to withdraw papers on this subject that have been submitted to the Fifth International Symposium on Neutron Capture Therapy.

With the exception of a small number of color and font problems, researchers have completed the "new body in slice," "copy body to slice," and "edit body in slice" tasks towards completion of the April 30, 1992, milestone of the medical image reconstruction and display module. Work is about $10 \%$ completed on "add flex to body." Researchers have begun work on the three-dimensional viewing widget and local data structures. It is anticipated that completion of the view window, with its associated scales for rotating the three-dimensional representation of bodies will be ready shortly. Contouring of the image has been completed using the National Academy of Sciences (NCAR) Library and the contouring will next be integrated into the existing $X$-Windows widgets. In addition, work has begun on the main window design with all its associated tool logos, menus, and widgets. A solution to the persistent p-oblem of different colors on different workstations has been found that involves a local resource file called BNCT_edit. This should allow BNCT edit to "look" the same, as well as feel the same, on all brands of workstations.

Task 4B: Microdosimetric Model Development

Work on this task, including microdosimetric analysis and "compound factor" evaluation, has been suspended because of funding restrictions. It will be necessary to withdraw a paper on this subject that has been submitted to the Fifth International Symposium.

Task 4C: Microdosimetric Cellular Response
Study

The SVEC4- 10 cells continue to show dramatic changes in their growth, growing rapidly for a time and then suddenly dying out. These cells are presently being used to gather baseline cellcycle kinetic data. They grow in an unusual manner and maintaining them is a continual learning experience; however, more knowledge is gained regarding their idiosyncracies with each cell passage.

Pacific Northwest Laboratories (PNL) researchers began three sequences of experiments: (a) time lapse studies of clonal development, (b) population number studies of division rate as a function of population density, and (c) reproductive survival following $x$-ray exposure to establish the low-linear energy transfer (LET) radiation sensitivity to characterize these cells.

The preliminary time lapse sturies performed in January 1992 showed that when these cells divide, the daughter cells usually move apart and reattach several cell viameters from each neighboring cell. As the number of cells in a clone increases, the individuals are gradually forced closer together. This may be responsible for the unstable behavior of these cultures. Crowding may constitute a stress that renders them very sensitive to nutritional or other changes. On the other hand, the fact that daughter cells move apart (rather than civerlapping for several hours as Chinese ovary $(\mathrm{CHO})$ cells do] will make it easier to determine the reproductive capacity of each daughte: cell for the first few divisions after irradiation. The current time lapse studies will investigate this with low-LET irradiation in preparation for studies with high-LET single particles.

Because of unexpected problems with alignment and indexing of the motor-driven lens turret [that carries both the objective and the photo multiplier tube (PMT)] on the microbeam irradiation apparatus, PNL researchers have been unable to irradiate cells. New apparatus has been designed and constructed that will move the lens to a positive stop. This should be installed in April and ready for use shortly thereafter.

\section{Task 4D: Proton-Induced Biological Damage Study}

RBE and Alternate Models: Neutron Technology Corporation (NTC) researchers have completed a careful examination of the general hypothesis and model put forward by Bond, his colleagues, and others (Bond, et al., 1985, 1991; Morsten, et al., 1989; Sondhaus, 1990). 
The model is intended to be a replacement for RBE or quality factor, $Q$, in dealing with mixed radiation fields. Probably the best overall furmulation is that of Morsten, which subsumes much of the prior work. The general theory proposes in common with most microdosimetric models that the outcome with any given dose is the result of convolution of two stochastic terms, one describing the physical distribution of ionizing events, and the second describing the biological or cellular response function. The latter is usually not known. The expression, as proposed by Morsten, et al., is the following. $E(D)$ is the biolc.gical response for a given dose from

$$
E(D)=\int f(z, D) \epsilon\{z, f(z, D)\} d z
$$

a radiation field of specific energy, $f(z, D)$ and $\epsilon$, the biological response function, which is associated with $z$ and $f(z, D)$. Unfortunately, the formalism of the model is limited to domains of dose such that there is a low probability that a single cell will be hit more than once. Under these conditions, the "hit size effectiveness function" (HZEF) proposed by the authors can be shown to be simply related to the initial slope of the dose response curve. Their model works adequately for the low-dose phenomena that they have investigated (i.e., point mutations in cellular systems). Researchers have, however, observed that their plotted HZEF are essentially normal Gaussian distributions (often called "error functions" by physicists), and, in the end, pretty much devolve to the classical Lea hit theory involving target size.

Microdosimetric formalism always assumes that the radiation target in the cell is a homogeneous volume of uniform radiation sensitivity and that ionization within this target is effective without consideration of the distribution of ionizing events within the target volume. Since the distribution of these events in the volume is itself stochastic, there must be acceptance of important "averaging", or "smoothing" of effectiveness within the volume. Furthermore, the dimensions of the target or targets in the microdosimetric sense are large fractions of a micron, rather than the nanometer target volumes believed to exist in the cell.

There may be some value to the use of the HZEF at very low doses, but, for the applications to clinical radiotherapy considered in this study, it is clear that there is no significant application to be found. Researchers remain convinced that the only possible hope for finding a replacement for the usual RBE (ratio of doses for a given effectiveness) lies in the proposed fluence-based approach of Curtis, et al., 1992. So far, this model has only been applied, again, to low-dose effects, but continuing research should develop approaches of some value for high-dose, normal tissue response endpoints.

Critical Cell-Killing Models and Vascular Endothelium: One important issue raised in earlier reports was whether there was some critical cell survival fraction for the clonogenic cells of the vascular endothelium that was essential for the integrity of function of the blood vessels of the brain. A brief examination indicated that such a fraction could not be defined, but NTC researchers have made a more careful examination of the data before discarding the concept. In brief, there is no reason to suggest that there is such a critical surviving fraction in the vascular endothelium.

The clonogenic cells of the microvasculature of the brain, as well as those of other tissues, can be assumed to be generally noncycling cells, and as such, normal radiobiological wisdom would lead one to assume that they are relatively insensitive to killing by ionizing radiation. Under normal conditions of replacement and repair (turnover) of the cells of the microvasculature, only a few cells would be found in cycle and radiosensitive at any time. An important contribution to our understanding of the radiosensitivity of the microvasculature is due to Hopewell, et al., 1986. These authors examined the number of remaining endothelial cells in the choroid plexus of the rat brain as a function of time and dose after radiation exposure. The reduction in number was highly significant, and time and dose related. However, the time and dose relationships were as one would predict for noncycling cells. A dose of $17.5 \mathrm{~Gy}$ produced only a one-third reduction in the number of endothelial cells, and it took nearly a year to see the maximum depression in number. Even a dose as high as $25 \mathrm{~Gy}$ only reduced the number by about two-thirds from control level, and, again, the time for depression was measured in weeks. Associated with the cell loss, however, was strong indications of reactive and regenerative changes that are common in microvasculature damaged by radiation. 
One must conclude from the foregoing data that normal cell killing of cycling clonogenic cells is not part of the picture of vascular degeneration following irradiation. Doses for cell killing would be lower and response times would be shorter.

The widely-accepted phenomenon of a "volume effect" associated with vascular degeneration and other damage in the CNS states that as the volume of tissue irradiated increases, the sensitivity is radiation damage also increases. Although the volume effect is considered to be central in planning radiotherapy of the CNS, data supporting such an effect are extremely limited. Two recent oral reports at the Annual Meeting $c:$ the Radiation Research Society were not supportive of this concept. Hopewell reported that he could find no volume effect in the irradiation of the spinal cord of swine, and Gillette reported there was minimal volume effect in the irradiation of the canine spinal cord. The volume effect for the CNS in man is even less well documented. Boden 1948 reported increased sensitivity of the spinal cord for larger volumes, but the data was not convincing.

The convincing animal data was that of Hopewell 1987 and van der Kogel 1987. They both showed that for spinal cord lengths of less than $1.5 \mathrm{~cm}$, the sensitivity increased dramatically. Of course, both authors explain this effect as the result of migration inward of functionally competent clonogenic cells capable of repairing the radiation damage. This migration from the edges of the damaged volume could only be effective over a short distance, thus explaining the limitation on the volume effect observed by them.

One can only conclude that there is no appropriate model for late damage in the CNS that can be attributed to survival of some specific portion or fraction of a clonogenic population.

\section{References:}

Boden, G., 1948, "Radiation Myelitis of the Cervical Spinal Cord," Br. J. Radiol. 21, pp. 516-519.

Bond, V. P. and M. N. Varma, 1985, "An Alternative to Absorbed Dose, Quality, and RBE at Low Exposures," Radiat. Res. 104, pp. S52S57.
Bond, V. P., A. L. Carsten, J. Bullis, S. P. Roth, 1991, "Severity of Organ Injury as a Predictor of Acute Mortality for Disparate Patterns of $A b$ sorbed Dose Distribution," Radiat. Res. 128, pp. S9-S11.

Curtis, S. B., L. W. Townsend, J. W. Wilson, P. Powers-Risius, E. L. Alpen, R. J. M. Fry, 1992, "Fluence-Related Risk Coefficients Using the Harderian Gland Data as an Example," $A d v$. Space Res. 12, pp. 407-416.

Hopewell, J. W., W. Calvo, D. Campling, H. S. Reinhold, M. Resvani, T. K. Yeung, 1989, "Effects of Radiation on the Microvasculature," Radiation Tolerance of Normal Tissues, J. M. Vaeth and J. M. Meyer (eds), Front. Radiat. Ther. Oncol. 23, pp. 85-95.

Hopewell, J. W., A. D. Morris, A. Dixon Brown, 1987, "The Influence of Field Size on the Late Tolerance of the Rat Spinal Cord to Single Doses of X-Rays," Br. J. Radiol. 60, pp. 1099-1108.

Hopewell, J. W., D. Campling, W. Calvo, H. S. Reinhold, J. H. Wilkinson, T. K. Yeung, 1986, "Vascular Irradiation Damage; Its Cellular Basis and Likely Consequence," Br. J. Cancer 53, Suppl. VII, pp. 181-191.

Morsten, K., V. P. Bond, J.W . Baum, 1989, "Probabalistic Approach to Obtain Hit-Size Effectiveness Function Which Relate Microdosimetry and Radiobiology," Radiat. Res. 120, pp. 383-402.

Sondhaus, C. A., V. P. Bond, L. E. Feinendegen, 1990, "Cell Oriented Alternatives to Dose, Quality Factor, and Dose Equivalent for Low-Level Radiation," Health Physics 59, pp. 35-48.

van der Kogel, A. J., "Effect of Volume and Localization on Rat Spinal Cord Tolerance," Radiation Research, Vol. I, E. M. Fielden, J. F. Hendry, J. H. Scott (Eds), Taylor and Francis, New York, NY, p. 352. 


\section{TECHNICAL SUPPORT CORE ACTIVITIES}

Task 1: ICP-AES Analyses of Boron in Biological Somples

Samples received

Samples prepared for analysis

$\sim 956$

Samples analyzed

$\sim 928$

Backlog:

Awaiting preparation

$\sim 1175$

Prepared, awaiting analysis

One ICP-AES instrument is not operational because of computer memory problems. The second instrument is operational and being scheduled for various projects.

Task 2: Boron Compound Purity Determinations

Purity analyses were completed on one batch of natural boron BSH from Callery Chemical Company. The compound was packaged individually in vials containing 5 grams BSH each. One vial representing Lot No. BNCT-426 (corresponding to Callery Lot No. 2351-59-1, $\# 91-151)$ was used for all sample analyses. A one-gram sample from the Lot was also archived.

HPLC Results: To compare the Callery Chemical sample with previous chemical purity results, other BNCT inventory samples were chromatographed with the new Callery Chemical sample as points of reference. HPLC conditions consisted of flow rate $0.4 \mathrm{~mL} / \mathrm{min}$ through a new Nucleosil ${ }^{\star}$-18 column, 250$\mathrm{mm}$ long, with a 3-mm inner diameter packed with 5- $\mu \mathrm{m}$ particles. The new column was purchased on a trial basis to determine if the chromatngraphy could be improved and waste minimized by utilizing a smaller inner diameter column and a smaller particle size for the stationary phase. It appears that the chromatography was enhanced by the new column conditions. The mobile phase used was approximately a $50 \%$ methanol $/ 50 \%$ water solution with $5 \mathrm{mM}$ tetra butyl ammonium sulfate (TBAS) as the ion-pairing reagent. These conditions are ideal for evaluating the $\mathrm{B}_{24} \mathrm{H}_{22} \mathrm{SS}^{4}$ (BSS) and $\mathrm{B}_{24} \mathrm{H}_{22} \mathrm{~S}_{2} \mathrm{O}^{4}$ (BSSO) component concentrations and integrity. However, these chromatographic conditions do not provide a clear separation of the $\mathrm{B}_{12} \mathrm{H}_{12}{ }^{2 \cdot}$ component from the BSH component. A slower flow rate is necessary for assessing presence of $\mathrm{B}_{12} \mathrm{H}_{12}{ }^{2 \cdot}$. The new sample and a reference sample (BNCT-202) were rerun at a flow rate of $0.3 \mathrm{~mL} / \mathrm{min}$ with all other conditions being nearly the same. The $\mathrm{B}_{12} \mathrm{H}_{12}{ }^{2}$ species could not be positively identified at appreciable concentrations in the new product.

A summary of the chromatographic results is shown in Table 2 and sample chromatograms of the new Callery Chemical sample, together with the reference sample (BNCT-202), are shown in Figure 5 (where Nucleosil $\mathrm{C} 18=$ 120-5, flowrate $=0.4 \mathrm{~mL} / \mathrm{min}$, eluent $=\sim$ $50 \%$ methanol with $5 \mathrm{mM}$ TBAS, injection = $20 \mu \mathrm{L}$, and ultraviolet detection $=215 \mathrm{~nm}$ ). The new sample was prepared in triplicate and the reference sample was prepared separately for each run. The Callery Chemical material does have the typical late-eluting unknown components, however, the concentration is considerably less than that of the reference sample (BNCT-202). Some BSS and BSSO are detectable, but the components are within the acceptable range.

ICP-AES Analysis: Elemental analysis for B, S, and $\mathrm{Na}$ by ICP-AES were performed on aliquots of all samples and standards prepared for HPLC. The results of this analysis are shown in Table 3. The results for BNCT-426 were consistent for all aliquots taken from the vial, indicating that no significant weighing errors occurred during preparation. The $\mathrm{B}: \mathrm{S}, \mathrm{B}: \mathrm{Na}$, and $\mathrm{Na}: \mathrm{S}$ ratios are quite typical.

Carbon-hydrogen-sodium (CHN) Combustion Analysis: A nitrogen atmosphere was utilized as much as possible for the samples used in the combustion analysis. The results of these analyses are presented in Table 4 . Sulfur results are not reported since they are irreproducibly low. The weight percent for hydrogen may provide evidence that the older sample (BNCT-202) may have become "wet" at some time, most likely during handling. This "wetting" of older, used samples is particularly clear for BNCT-202 when comparing compound taken from the subsample vial used for all previous analyses and the original vial. Carbon is also present and notable in all of the new materials. 
Table 2. Oxidation Products in Various BSH Samples as Determined by HPLC.

\begin{tabular}{cccc}
\hline Sample & Compound & BSS (wt \%) & BSSO (wt \%) \\
\hline 202 & $\mathrm{Na}_{2} \mathrm{~B}_{12} \mathrm{H}_{1} \mathrm{SH}$ & $3.18 \pm 0.07$ & $0.078 \pm 0.004$ \\
426 & $\mathrm{Na}_{2} \mathrm{~B}_{12} \mathrm{H}_{11} \mathrm{SH}$ & $0.7 \pm 0.2$ & $0.21 \pm 0.02$ \\
\hline
\end{tabular}

(a) All samples have been corrected for isotopic abundance.

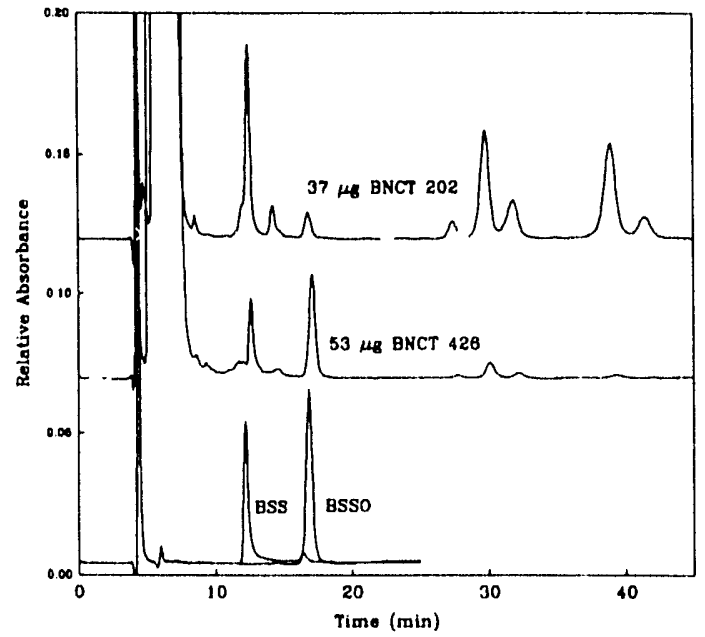

Figure 5. HPLC chromatograms of BNCT-426 and BNCT-202.
NMR Spectroscopy: The natural abundance boron NMR spectra of the new Callery Chemical BSH were unremarkable as it confirmed that BSH was the main boron-containing species in each vial.

FTIR Spectroscopy: The preparation of the infrared samples was again performed entirely under nitrogen. The actual quantity of sample in each pellet was not accurately determined. Consequently, some pellets had more sample material in them than others and the spectra in Figure 6 have been normalized for clarity. All single-beam infrared spectra were ratioed to a single-beam spectrum of a blank $\mathrm{KBr}$ pellet. The spectra reveal the presence of water only in BNCT-202. The peaks in the BNCT-202 spectrum at $\sim 3500 \mathrm{~cm}^{1}$ and $\sim 1680 \mathrm{~cm}^{1}$ correspond with the presence of water.

Table 3. ICP-AES Analysis of BSH Compounds.

\begin{tabular}{|c|c|c|c|c|c|c|c|}
\hline \multirow[b]{2}{*}{ Sample } & \multirow[b]{2}{*}{ Compound } & \multirow{2}{*}{$\begin{array}{c}s \\
(w t \%)\end{array}$} & \multirow{2}{*}{$\begin{array}{c}B^{*} \\
(w t \%)\end{array}$} & \multirow{2}{*}{$\begin{array}{c}\mathrm{Na} \\
(w t \%)\end{array}$} & \multicolumn{3}{|c|}{ Mole Ratios } \\
\hline & & & & & B:S & $\mathrm{B}: \mathrm{Na}$ & Na:S \\
\hline 202 & $\mathrm{Na}_{2} \mathrm{~B}_{12} \mathrm{H}_{11} \mathrm{SH}$ & $12.3(3.0)^{b}$ & $56.0 \pm 0.8$ & $18.2(5.1)^{b}$ & $13.5(5.5)^{6}$ & $6.6(7.7)^{b}$ & $2.08(2.2)^{b}$ \\
\hline 210 & $\mathrm{Cs}_{4}{ }^{10} \mathrm{~B}_{24} \mathrm{H}_{22} \mathrm{~S}_{2}$ & 6.8 & $27.8(0.1)^{b}$ & & $12.4(8.7)^{b}$ & & \\
\hline 212 & $\mathrm{C}_{8}{ }^{10} \mathrm{~B}_{24} \mathrm{H}_{22} \mathrm{~S}_{2} \mathrm{O}, \mathrm{O}$ & $8.4(7.3)^{\mathrm{b}}$ & $26.0 \pm 0.9$ & & $12.9(1.9)^{b}$ & & \\
\hline 426 & $\mathrm{Na}_{2} \mathrm{~B}_{12} \mathrm{H}_{11} \mathrm{SH}$ & $14.2 \pm 1.1$ & $60.7 \pm 4.3$ & $20.7 \pm 1.3$ & $12.9 \pm 0.5$ & $6.3 \pm 0.2$ & $2.03 \pm 0.06$ \\
\hline
\end{tabular}

- All samples have been corrected for isotopic abundance.

Values in parentheses represent the relative percent difference (RPD) between two aliquots.

Table 4. CHN Combustion Analysis Results (3/11/92).

\begin{tabular}{cccc}
\hline Sample & $C(w t \%)$ & $H(w t \%)$ & $N(w t \%)$ \\
\hline 202 & $0.73 \pm 0.08$ & $6.79 \pm 0.12$ & 0 \\
426 & $0.15 \pm 0.06$ & $6.21 \pm 0.39$ & 0 \\
\hline
\end{tabular}


The infrared spectrum of the Callery Chemical product (BNCT-426) has little, if any, water and only a slight absorbance that is attributable to a C-H at $\sim 2900 \mathrm{~cm}^{1}$. This relates nicely to the presence of $C$ as determined by the CHN analysis. A similar absorbance also appears to be present in the BNCT-202 spectrum.

Task 3: Intra- and Intercellular Boron Analyses

Secondary lon Mass Spectrometry (SIMS): An overview of SIMS research being performed by Charles Evans \& Associates (CE\&A) is presented. Efforts are directed toward acquiring quantitative images at the cellular level. Good spatial resolution is required to resolve the cellular features of interest and high instrumental sensitivity is needed to detect boron at the low ppm concentration levels. Three research tasks are currently underway to achieve this goal: (a) developing accurate biological standards to be used for quantification, (b) instrumentation research of a Time-of-Flight (TOF) SIMS instrument to obtain $200 \AA$ spatial resolution images with high elemental and molecular sensitivity, and (c) developing tissue sample preparation protocols for SIMS imaging. (Appropriate biological standards are necessary for acrurate quantitative SIMS imaging.) This task is proceeding in close collaboration with INEL researchers, who are preparing the standards and using ICP-AES to standardize the boron-doped concentrations. Experiments have been performed using agarose, gelatin, and brain homogenates as potential standard matri

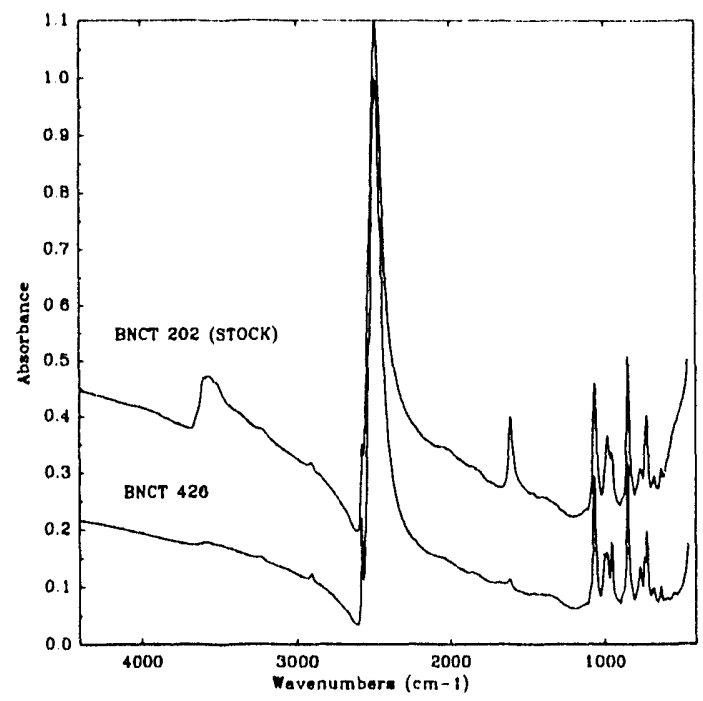

Figure 6. Infrared spectra of BSH samples in $\mathrm{KBr}$ pellets. ces. The conclusion is that the most accurate standard matrix for imaging brain tumor tissties is the brain homogenate.

The first research task utilizes boron standards analyzed as ${ }^{10} \mathrm{BSH}$ and natural $\mathrm{H}_{3} \mathrm{BO}_{3}$ in brain homogenates. A second set of samples consisting of boron as natural BSH and $\mathrm{H}_{3}{ }^{10} \mathrm{BO}_{3}$ is being prepared and will be analyzed as soon as possible. These analyses are performed using a Cameca double-focussing mass spectrometer in a dynamic SIMS mode. The purpose of these experiments is to determine if the boronto-carbon ratio is independent of the boron origin and, if this is true, to obtain a boron calibration plot for a brain matrix (B/C ratio vs boron concentration) from which SIMS images can be quantified. The brain homogenates prepared by INEL researchers are made with approximately $20 \mathrm{~mL}$ of a $0.9 \% \mathrm{NaCl}$ solution, which is necessary to pipette the homogenates onto Si wafers for analysis. The resulting airdried residues are uniformly distributed showing no surface features (ideal for SIMS analysis). Preliminary experiments indicate that a change in carbon ion yield is only significant from homogenates diluted greater than $50 \%$. The concluding experiment is to image and determine the boron concentration in tissue, and compare it to serial tissue analysis by ICP-AES.

The second task involves using a TOF-SIMS instrument, designed and manufactured at CE\&A, for acquiring high, spatial resolution SIMS images. Previous images were taken using the Cameca unit equipped with a $\mathrm{Cs}^{*}$ ion source operating in an ion microscope mode. A schematic of the TOF-SIMS instrument is shown in Figure 7. The system is equipped with a $\mathrm{Cs}^{+}$ion source for ion microscope analysis and a liquid metal ion gun (LMIG) Ga * microbeam source for ion microprobe analysis. Ion microscope analysis uses a large diameter $(>300 \mu \mathrm{m})$ primary ion beam and forms mass resolved ion images by projecting the lateral distribution of secondary ions formed at the surface onto a two-dimensional image detector. Ion microscope image resolution is typically $1-5$ $\mu \mathrm{m}$. Ion microprobe TOF-SIMS uses a finelyfocussed primary beam, rastered about the sample surface. Ion microprobe image resolution is determined by the primary beam diameter (typically $0.2 \mu \mathrm{m}$ ). 


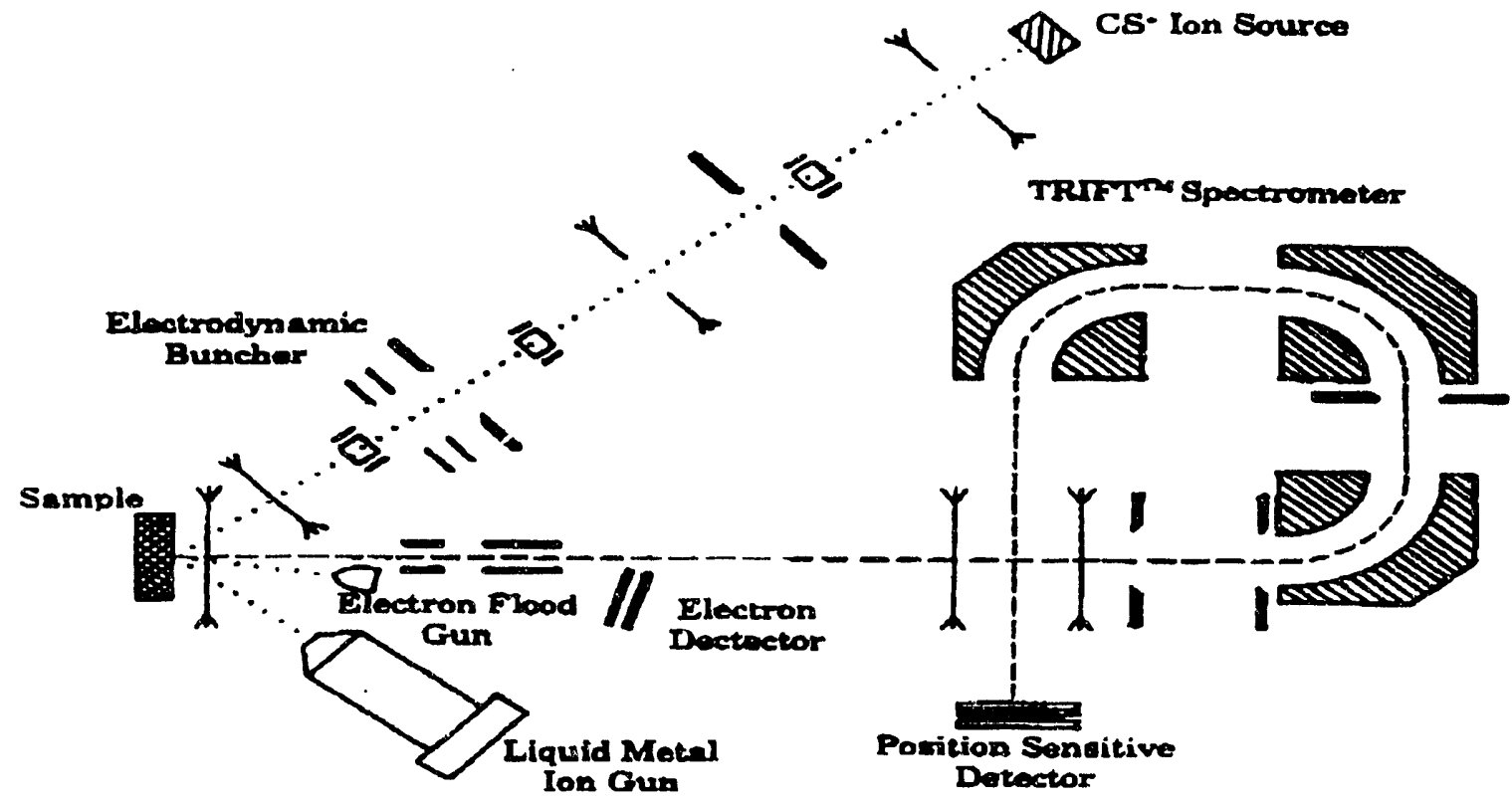

Figure 7. Cross sectional view of the TFS surface analyzer.

The positive secondary ion images of a model membrane surface, composed of phosphatidylcholine covalently attached to silica particles with the polar end groups exposed, illustrate the present spatial resolution of this instrument operating in the ion microprobe mode. The beads are typically $7-12 \mu \mathrm{m}$ in diameter and are randomly distributed onto a carbon substrate. The total secondary ion image of a selected area on the wafer shows pseudo three-dimensional images of the spheres. (Graphic output of the instrument is in the form of color enhanced plots of the surface. Since this report is not printed in color, a great deal of information available about the surface cannot be presented.) It is extremely important to realize that sample surface inhomogeneities can produce artifact features in a SIMS image. Matrix ion intensity nurmalization is, therefore, routinely performed to determine if a feature is intrinsic to the sample surface. Another example is available which shows the total secondary ion, boron, and sodium images acquired from a selected region from skin No. 3 of dog No. 2174. Boron is observed in the tissue and in the voids confirming previous results using the Cameca unit that leaching of boron proba- bly occurred during sample preparation. In contrast, sodium is observed only in the tissue region. Research into improving detection efficiency of organics using postionization and postacceleration techniques is continuing.

The fact that quality samples (viable tissues with a flat surface) is a prerequisite requirement for quality SIMS imaging leads directly to the reason why the third task is in proyress. Tissue samples received to date for SIMS imaging have been unsuitable. Tissue sample preparation procedures are being developed in collaboration with WSU researchers. The general protocol is to cryofix the viable tissue, cryoultramicrotome the frozen tissue (if necessary), followed by freeze-drying. This procedure is more difficult to perform than chemical fixation; however, the advantages of cryofixation are very significant. For example, leaching of endogenous diffusible elements and loss of organic compounds during dehydration and embedding steps are eliminated in this procedure. Concentration buildup of diffusible elements in artifactual locations due to concentration gradients in the tissue and preferentiallybound sites are also eliminated. 
CE\&A researchers have available a metal mirror cryofixation unit and a cryoultramicrotome. The next step to achieving the goals of the third task was to design and build a freezedryer unit (shown in Figure 8). No commercial apparatus was available that met both the requirements of operating with oil-free pumps and operation as a dry box. Temperature testing and preliminary experiments are currently in progress.

It is evident from this research overview that the success of acquiring quantitative SIMS images in biological tissues at the cellular level is dependent on achieving the goals set for all three tasks. It is relevant to mention that the TOF-SIMS instrument used in these experiments represents the state-of-the-art in SIMS ion microscope and ion microprobe instrumentation. Coordinating the tasks is also essential in maintaining the momentum of commitment to the INEL BNCT Research Program.

\section{Sputter Initiated Resonance lonization Soectros-} copy (SIRIS): Mouse tissue samples were prepared by Dr. Robert Switzer of the University of Tennessee Medical Research Foundation (UTMRF) and provided to Atom Sciences, Inc.
(ASI) researchers. The material was obtained from Dr. George Kabalka (also of UTMRF) after completion of boron MRI experiments by Dr. Kabalka. The mouse had approximately a $1-\mathrm{cm}$ diameter, artificially-induced tumor growing in its abdomen and had been BSH-infused for approximately one week with an internal osmotic pump. Abdominal tumor, brain, kidney, and liver tissues were collected and quickfrozen in liquid nitrogen within less than one hour after necrosis. These tissues were sectioned to approximately $20 \mu \mathrm{m}$ thickness (while frozen) and mounted alternately onto goldcoated, stainless-steel sample holders (provided by ASI) and glass slides for histological reference. The SIRIS samples were freeze-dried, while the histological samples were stained.

Preliminary examination indicates that these samples have better adherence to the substrate and should provide a more easily interpreted result with SIRIS analysis. ASI researchers have also begun preliminary experiments to utilize laser atomization combined with RIS to image the boron concentration in tissues. Results are pending.

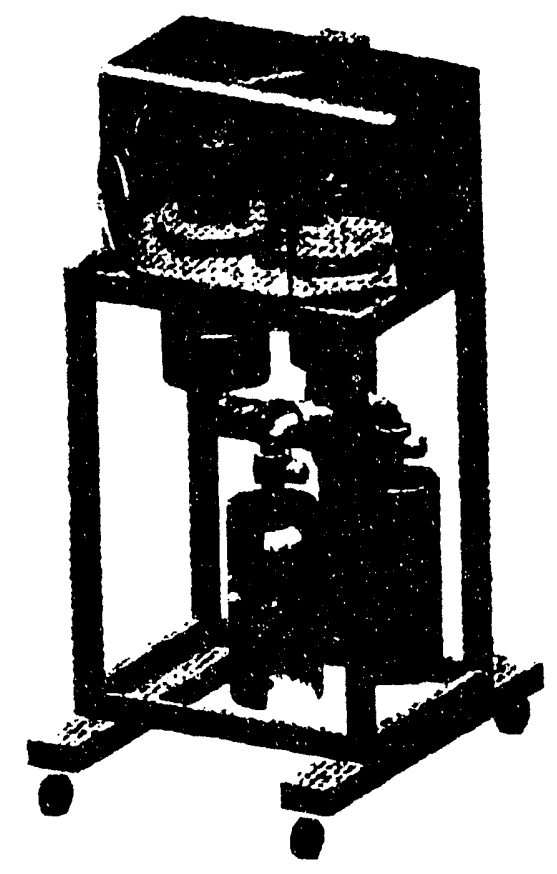

Figure 8. Freeze-dryer sample preparation system. 

Task 4: Neutron Beam Measurement

No reportable progress.

\section{Task 5: Canine Dosimetry Calculations}

Three dose-tolerance dogs were irradiated at BMRR the week of April 6, 1992. A fourth dog was scheduled, but the reactor was shut down for an operational problem and the irradiation could not be done. The planned total dose for each dog was $1900 \mathrm{cGy}$ and the planned average boron loading was 25 ppm.

Work continues on preparation of the data from the tumor dog optimization study for presentation. Calculations for all four dogs in the BMRR beam have been completed. An initial calculation for one dog in the proposed Georgia Institute of Technology Research Reactor (GTRR) beam has also been completed. The results indicate that all things being equal, one or two orders of magnitude increase in cell kill can be obtained in the GTRR beam relative to what could be optimally obtained with the BMRR beam (using BSH in both cases). This was as expected, based on the angular and spectral characteristics of the two beams.

\section{Task 6: BNCT Database Management System}

There has been no activity on this task. Further work has been suspended because of budget limitations.

\section{Task 7: GTRR Physics Support}

There was no reportable additional activity because of budget constraints and programmatic uncertainty. The conceptual design is essentially complete and will be presented at the special BNCT session planned for the June 1992 American Nuclear Society (ANS) meeting. A paper on this beam has also been submitted to the Fifth International Symposium, but will be withdrawn. Work on this task was suspended at month end because of funding restrictions.

Task 8: Research Reactor/Accelerator Physics Support

No activity because of budget constraints.
Fifth International Symposium for Neutron Capture Therapy

Thirty-nine abstracts were submitted without registration fees for the September meeting in Columbus, Ohio. It will be necessary to withdraw some of these papers as a result of funding limitations and Program redirection.

\section{Publications:}

The following abstracts/papers were prepared and submitted for DCIE clearance/approval:

1. T. R. LaHann, W. F. Bauer, and D. R. Lu, "Enhanced Delivery of Para-Boronophenylalanine by 2-Hydroxypropyl-beta-Cyclodextrin," Fourth International Symposium on Polymeric Drugs and Drug Delivery Systems, in Washington, D.C., August 24-29, 1992.

2. P. A. Radel and S. B. Kahl, "Enantioselective Synthesis of L-Carboranylalanine," Medicinal Chemistry Symposium, University of Buffalo, Buffalo, NY, June 14-18, 1992.

3. C. A. Elstad, K. R. Meinkoth, B. A. Mathison, T. C. Senter, G. G. Meadows, D. H. Kinder, M. F. Hawthorne, and W. F. Bauer, "Uptake of Boronated Compounds by Murine Melanoma," Boron USA III Workshop at Washington State University, Pullman, WA, July 8-11, 1992.

4. M. F. Hawthorne, K. Shelly, D. A. Feakes, P. G. Schmidt, T. A. Krisch, and W. F. Bauer, "Model Studies Directed Toward the Boron Neutron Capture Therapy of Cancer: Boron Delivery to Murine Tumors with Liposomes," Proceedings of the National Academy of Science.

5. D. H. Kinder, C. A. Elstad, and G. G. Meadows, "In Vivo Activity and Distribution of Tripeptide Boronic Acid Analoi? Protoase Inhibitors in B16/BL6 Murine Melanoma," Boron USA III Workshop at Washington State University, Pullman, WA, July 8-11, 1992.

Miscellaneous: 

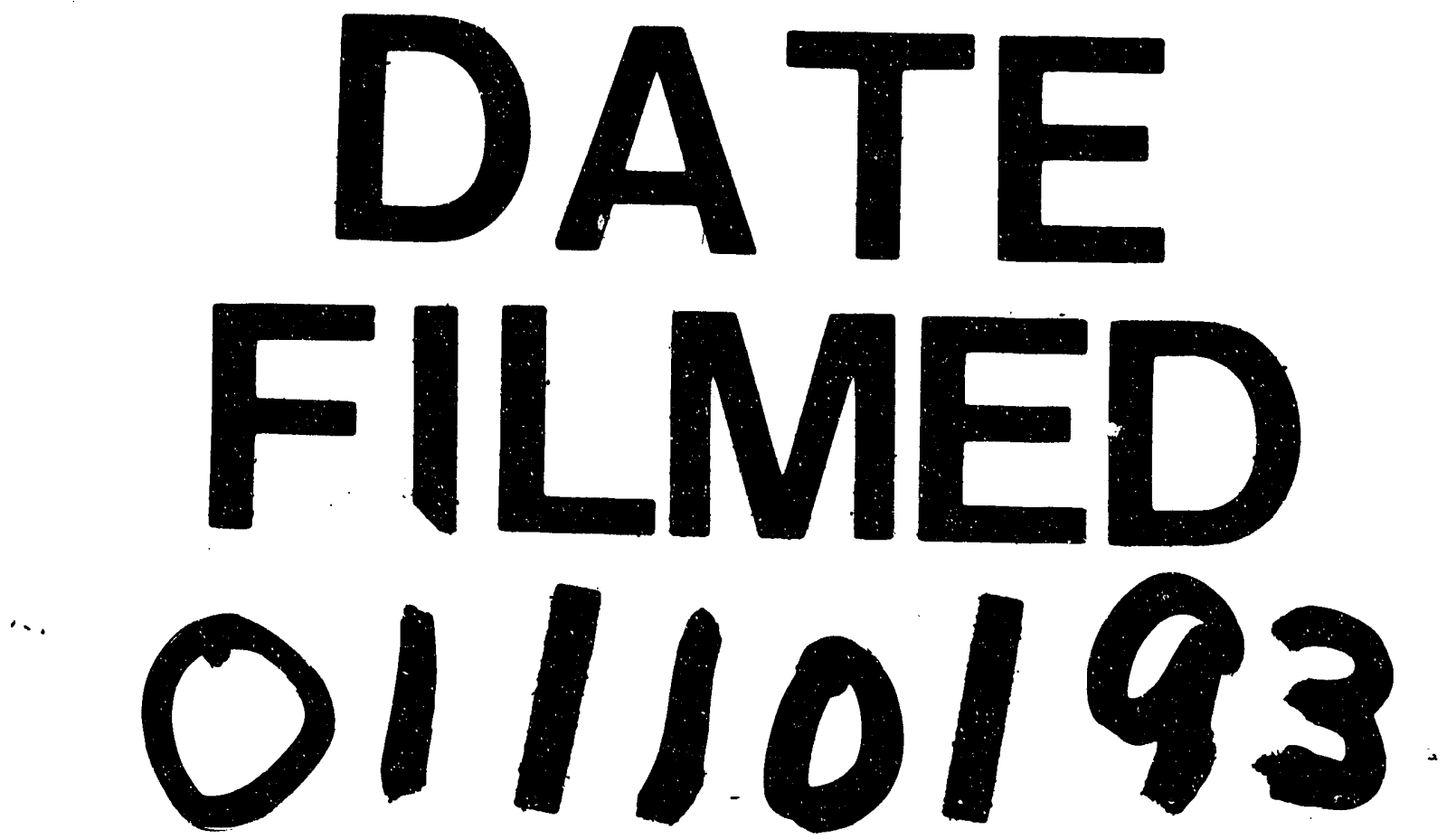

童 
